\title{
Suspended sediment transport around a large-scale laboratory breaker bar
}

\author{
J. van der Zanden ${ }^{\mathrm{a}, *}$, D.A. van der A ${ }^{\mathrm{b}}$, D. Hurther ${ }^{\mathrm{c}}$, I. Cáceres ${ }^{\mathrm{d}}$, T. O’Donoghue ${ }^{\mathrm{b}}$, J.S. Ribberink ${ }^{\mathrm{a}}$ \\ a Department of Water Engineering and Management, University of Twente, Netherlands \\ b School of Engineering, University of Aberdeen, United Kingdom \\ ${ }^{\mathrm{c}}$ Laboratoire des Ecoulements Géophysiques et Industriels LEGI-CNRS, Université Grenoble Alpes, France \\ a Laboratori d'Enginyeria Maritima, Universitat Politècnica de Catalunya, Spain
}

\section{A R T I C L E I N F O}

\section{Keywords:}

Breaking waves

Sediment transport

Suspended sediment

Wave bottom boundary layer

Surf zone

Wave flume experiment

\begin{abstract}
A B S T R A C T
This paper presents novel insights into suspended sediment concentrations and fluxes under a large-scale laboratory plunging wave. Measurements of sediment concentrations and velocities were taken at 12 locations around an evolving breaker bar, covering the complete breaking region from shoaling to inner surf zone, with particular high resolution near the bed using an Acoustic Concentration and Velocity Profiler. Wave breaking evidently affects sediment pick-up rates, which increase by an order of magnitude from shoaling to breaking zone. Time-averaged reference concentrations correlate poorly with periodic and time-averaged near-bed velocities, but correlate significantly with near-bed time-averaged turbulent kinetic energy. The net depthintegrated suspended transport is offshore-directed and primarily attributed to current-related fluxes (undertow) at outer-flow elevations (i.e. above the wave bottom boundary layer). The wave-related suspended transport is onshore-directed and is generally confined to the wave bottom boundary layer. Cross-shore gradients of sediment fluxes are quantified to explain spatial patterns of sediment pick-up and deposition and of cross-shore sediment advection. Suspended particles travel back and forth between the breaking and shoaling zones following the orbital motion, leading to local intra-wave concentration changes. At locations between the breaker bar crest and bar trough, intra-wave concentration changes are due to a combination of horizontal advection and of vertical exchange with the bedload layer: sediment is entrained in the bar trough during the wave trough phase, almost instantly advected offshore, and deposited near the bar crest during the wave crest phase. Finally, these results are used to suggest improvements for suspended sediment transport models.
\end{abstract}

\section{Introduction}

Over the last decades, experimental and numerical studies have significantly advanced the understanding of sediment transport processes and the ability to predict suspended and bedload transport rates for non-breaking waves [65]. However, in the breaking region, existing formulations for suspended sediment concentrations and transport may not be valid due to effects of breaking-generated turbulence and of cross-shore hydrodynamic non-uniformity (i.e. cross-shore changes in wave shape and undertow) which are not fully understood [65].

Laboratory $[43,52,67]$ and field studies $[31,6,70]$ have reported large amounts of suspended sediment in the breaking zone, related to the enhancing effects of breaking-generated vortices on sediment entrainment from the bed $[1,28,31,48,53,67]$ and on vertical sediment mixing $[2,31,35,68]$. These processes depend on the characteristics of the breaking wave, with plunging breakers being more effective in entraining and mixing sediment than spilling breakers [2,31]. This relates to differences in turbulence behavior, with higher production rates and a more rapid downward spreading of breaking-induced turbulence found under plunging than under spilling waves [58].

Due to the dominance of breaking-induced vortices on sediment pick-up, existing formulations for near-bed reference concentrations that are based on orbital and time-averaged velocities [32,64] may not apply in the wave breaking region [2]. Instead, formulations that are based on breaking-induced turbulence and that take the breaker type into account (e.g. $[27,52,24]$ ) appear more appropriate. An additional complication is that due to strong horizontal sediment advection in the breaking region $[48,69]$ the near-bed concentrations may not always be related to local hydrodynamics only.

The net horizontal suspended flux in the breaking region is the result of two opposing fluxes with similar magnitudes: an offshoredirected current-related flux and an onshore-directed wave-related flux $[34,37,46,57]$. The former is driven by the undertow, whereas the latter relates to the wave asymmetry $[17,19]$. Time-varying breaking-generated turbulence, with higher intensities during the crest half-cycle, has been suggested as an additional factor contributing to onshore wave-

\footnotetext{
* Corresponding author.

E-mail address: j.vanderzanden@utwente.nl (J. van der Zanden).
} 
related suspended sediment fluxes [58,7]. Yoon and Cox [69] presented experimental evidence for increased onshore wave-related suspension fluxes due to intermittent suspension events that occur preferentially during the wave crest phase following events of high turbulent energy. However, Scott et al. [48] found, by combining data from the same experiment with numerical simulations, that suspension events occur mainly during the wave trough phase and contribute to offshoredirected fluxes. The individual effects by turbulence and wave asymmetry on sediment fluxes are difficult to assess because the two parameters correlate positively in the breaking region $[67,1]$.

Although previous research highlighted clear effects of wave breaking on sediment suspension and fluxes, there are still open research questions. Most of the aforementioned studies are based on local point measurements of sediment concentrations at few elevations in the water column, sometimes combined with co-located velocity measurements to estimate the local sediment fluxes. These measurements did not capture the complete vertical distribution of fluxes since the nearbed region including the wave bottom boundary layer (WBL), where large contributions to total suspended transport can be expected, was not accurately resolved. Such measurements of WBL flow and timevarying near-bed turbulence are also essential in relating the observed sediment processes to hydrodynamic forcing. In addition, most of the previous experimental studies covered only a few cross-shore locations in the shoaling and breaking region. This strongly limits the study of cross-shore advection of suspended sediment and the effects of crossshore non-uniformity in hydrodynamics (i.e. flow and turbulence) on suspended sediment processes.

Here we present new high-resolution measurements of suspended sediment transport processes under a plunging wave in a large-scale wave flume. Measurements were obtained at 12 cross-shore locations along a sandy breaker bar, covering the complete breaking region from shoaling zone to inner surf zone. Sediment concentration and velocity measurements cover most of the water column, with particular high resolution of time-varying concentrations and sediment fluxes in the near-bed region (including the WBL). The aim is to improve insights into suspended sediment processes in the breaking region, with particular focus on the current-related, wave-related and turbulent suspended sediment flux components and their contributions to the total net suspended transport. These fluxes are also used to explain the intra-wave near-bed concentration field in terms of horizontal sedi- ment advection and vertical exchange of sediment between the suspension and bedload layer (pick-up and deposition). Results of the sediment dynamics are related to the detailed near-bed flow and turbulence measurements obtained from the same experiment and reported in van der Zanden et al. [62].

The paper is organized as follows: the experiment is described in Section 2. Section 3 presents the bed profile evolution and the crossshore variation in the main hydrodynamic parameters. Section 4 presents results on suspended sediment concentrations (4.1), fluxes and net transport rates (4.2) and horizontal advection and pick-up/ deposition (4.3). The results are used to discuss potential improvements to suspended sediment transport formulations, which are incorporated in numerical morphodynamic models used for engineering purpose, for breaking-wave conditions (Section 5).

\section{Experimental description}

\subsection{Facility and test conditions}

The experiments were carried out in the large-scale CIEM wave flume at the Universitat Politècnica de Catalunya (UPC) in Barcelona and have been described before in detail by van der Zanden et al. [62].

Fig. 1 shows the experimental set-up and bed profile. Cross-shore coordinate $x$ is defined positively towards the beach, with $x=0$ at the toe of the wave paddle. Vertical coordinate $z$ is defined positively upwards with $z=0$ at the still water level (SWL); $\zeta$ is the vertical coordinate positive upwards from the local bed level. The initial bed profile consisted of a bar-trough configuration that was deliberately separated from the shoreline so that the transport dynamics around the bar would not likely be affected by processes in the swash zone. The test section can be roughly divided into an offshore-facing bar slope $(x=$ 35.0 to $54.8 \mathrm{~m}$; steepness $\tan (\alpha)=1: 10$ ), followed by a steeper shoreward-facing bar slope $(x=54.8$ to $57.5 \mathrm{~m} ;-\tan (\alpha)=1: 4.7)$, and a mildly sloping bed shoreward from the bar trough $(x=57.5$ to $68.0 \mathrm{~m} ; \tan (\alpha)=1: 95)$. The test section consisted of medium sand (median diameter $D_{50}=0.24 \mathrm{~mm} ; D_{10}=0.15 \mathrm{~mm} ; D_{90}=0.37 \mathrm{~mm}$ ) with a measured settling velocity $w_{s}=0.034 \mathrm{~m} / \mathrm{s}$. The grain size standard deviation $\sigma_{g}=1.4$, quantified through the geometric method of moments, classifying the sediment as 'well sorted' [8]. The profile shoreward of the mobile test section $(x>68.0 \mathrm{~m})$ followed a 1:7.5
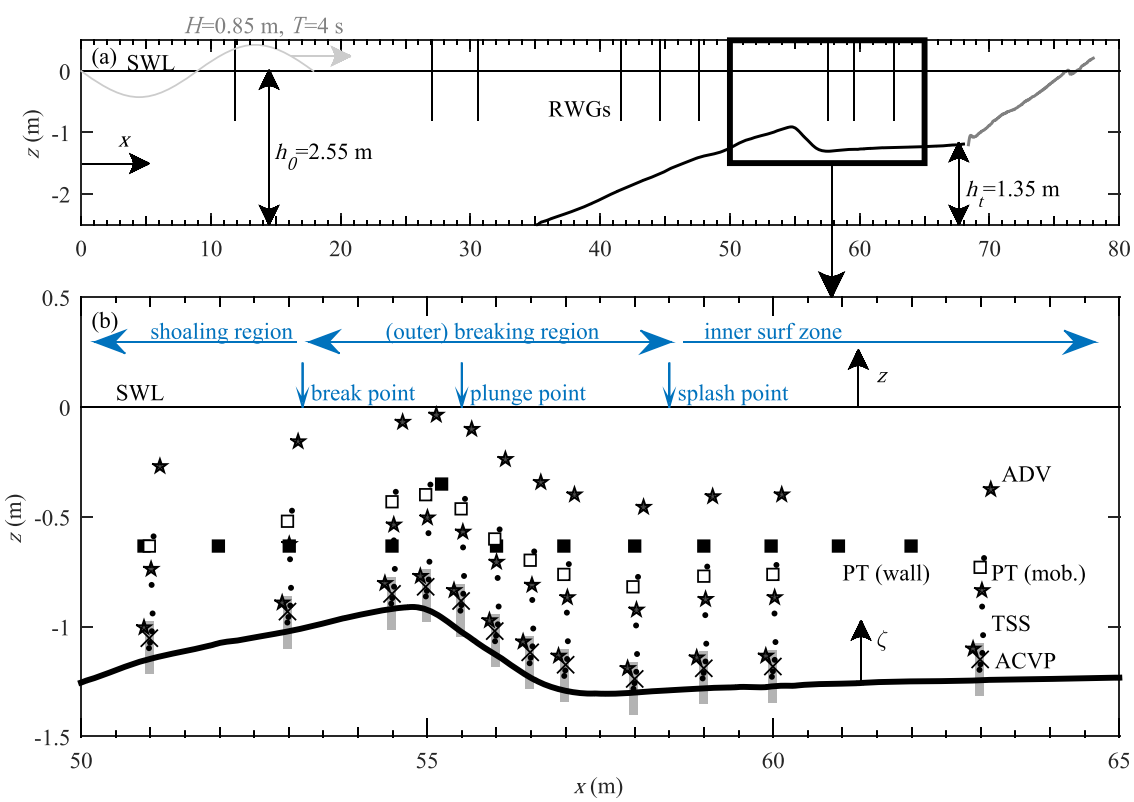

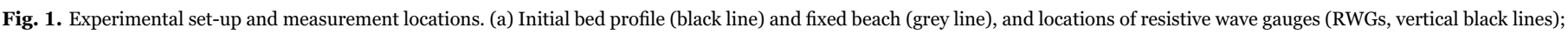

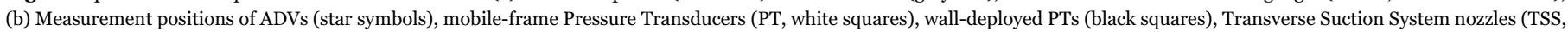
black dots), Optical Backscatter Sensor (black crosses), and measuring range of mobile-frame ACVP (grey boxes). 
slope, and was fixed with geotextile and covered with perforated concrete slabs to promote wave energy dissipation and reduce reflection.

Monochromatic waves with wave period $T=4 \mathrm{~s}$ and wave height $H_{0}=$ $0.85 \mathrm{~m}$ at water depth $h_{0}=2.55 \mathrm{~m}$ near the wave paddle were generated based on first-order wave theory. The wave condition corresponds to a surf similarity parameter $\xi_{0}=0.54$ (where $\xi_{0}=\tan (\alpha) / \sqrt{H_{0} / L_{0}} ; L_{O}$ is the deep-water wave length) and leads to a plunging-type breaking wave. Three distinct reference points of the breaking process are defined based on existing terminology [49]: the break point $(x=53.0 \mathrm{~m})$ where the breaking wave starts to overturn, the plunge point $(x=55.5 \mathrm{~m})$ where the plunging jet hits the water surface, and the splash point $(x=59.0 \mathrm{~m})$ where the pushed up water transforms into a surf bore. Definitions for the shoaling, breaking, and inner surf zones (see Fig. 1b) are based on these reference points following Svendsen et al. [55]. The wave paddle did not feature active wave absorption. The estimated reflection coefficient from the fixed beach is about 0.04 to 0.09 , estimated based on an empirical predictor [3].

\subsection{Instrumentation}

Most instruments were deployed from a custom-built mobile frame (Fig. 2) that could be positioned with cm accuracy in the cross-shore direction and sub-mm accuracy in the vertical direction [42]. The mobile frame set-up enabled an approximately equal elevation of the instrumental array with respect to the bed at the start of each run. Table 1 lists the vertical and cross-shore positions of the instruments.

Velocities were measured at three outer-flow elevations using 3component Acoustic Doppler Velocimeters (ADVs) with sampling frequency $f_{s}=100 \mathrm{~Hz}$, and near the bed with a 2-component (crossshore and vertical) Acoustic Concentration and Velocity Profiler (ACVP) [22]. The ACVP measured particle velocities over a vertical profile of 10 to $15 \mathrm{~cm}$ directly above the bed with $1.5 \mathrm{~mm}$ vertical sampling bin resolution and $f_{s}=70 \mathrm{~Hz}$. More details on the velocity measurement instrumentation can be found in van der Zanden et al. [62].

Time-averaged sediment concentrations were obtained with a sixnozzle Transverse Suction System (TSS), consisting of six stainlesssteel nozzles, each connected through plastic tubing to a peristaltic pump on top of the wave flume. Following Bosman et al. [9], the TSS was designed to have intake velocities of $2.3 \mathrm{~m} / \mathrm{s}$, i.e. exceeding the maximum orbital velocity by approximately 1.5 , in order to guarantee a constant sediment trapping efficiency. The nozzle intake diameter was $3 \mathrm{~mm}$ (same as [9]) and the pump discharge was $1 \mathrm{~L} / \mathrm{min}$. The $30 \mathrm{~mm}$

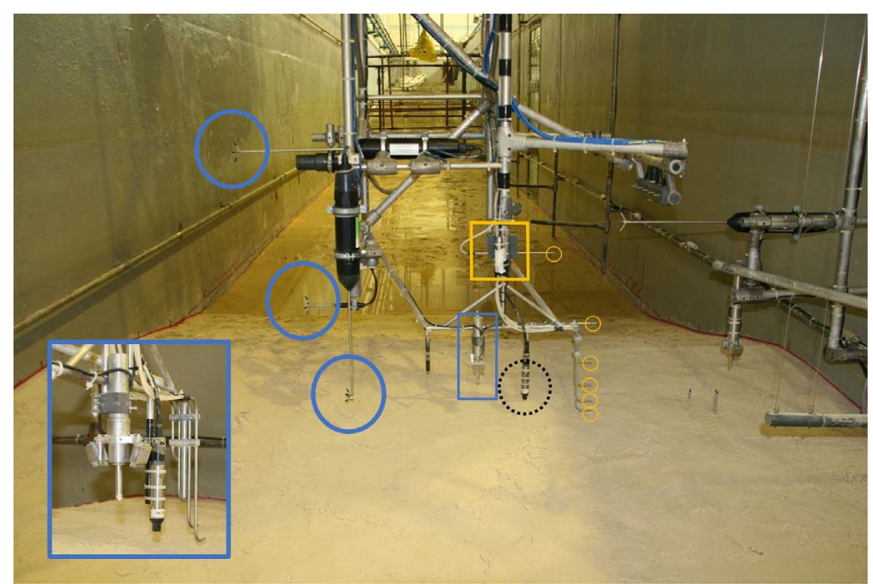

Fig. 2. Mobile measuring frame and instrumentation: three ADVs (blue solid circles), a Pressure Transducer (yellow square), a six-nozzle Transverse Suction System (yellow circles), an OBS (black dashed circle) and an ACVP (blue square). Inset shows close-up of near-bed instrumentation. (For interpretation of the references to color in this figure legend, the reader is referred to the web version of this article.)
Table 1

Positions of mobile-frame instrumentation: vertical elevation $\zeta$ with respect to initial bed level, and cross-shore distance $\Delta x$ with respect to the ACVP.

\begin{tabular}{lll}
\hline Instrument & $\boldsymbol{\zeta ( \mathbf { m } )}$ & $\boldsymbol{\Delta x}(\mathbf{m})$ \\
\hline Acoustic Doppler Velocimeters & $0.11,0.38,0.85$ & $-0.10,0.02$, \\
$\quad$ (ADVs) & & 0.14 \\
Acoustic Concentration and Velocity & 0.12 (elevation & 0 \\
$\quad$ Profiler (ACVP) & transmitter) & \\
Transverse Suction System & $0.02,0.04,0.10$, & $-0.02,0.00$, \\
$\quad$ (TSS) nozzles & $0.18,0.31,0.53$ & 0.02, \\
& & $0.03,0.02$, \\
& 0.07 & 0.05 \\
Optical Backscatter Sensor (OBS) & 0.48 & -0.01 \\
Pressure Transducer (PT) & & -0.01 \\
\hline
\end{tabular}

long nozzles were oriented parallel to the bed and perpendicular to the wave direction (Fig. 2).

The TSS tubing consisted of $2 \mathrm{~m}$-long, $4 \mathrm{~mm}$-diameter rigid air hose tubing at the lower part of the frame, and $4 \mathrm{~m}$-long, $8 \mathrm{~mm}$-diameter silicone tubing at higher levels. The estimated water velocity in the widest suction hose was $0.3 \mathrm{~m} / \mathrm{s}$, which exceeds the sediment settling velocity by an order of magnitude. The sampled water plus sediment mixture was captured in $15 \mathrm{~L}$ buckets, which were weighed (to measure the water content), carefully drained to remove excess water, transferred to aluminum cups, and then dry-weighed to give a first measure of the concentration $C_{s}$. The actual concentration $C_{\text {true }}$ is then obtained from $C_{\text {true }}=\beta_{t} C_{s}$, where the factor $\beta_{t}=1+1 / 3 \arctan \left(D_{50} / 0.09\right)$ is the inverse of the nozzle's trapping efficiency [9]. The estimated TSS measuring error due to the various processing steps (estimation of trapping efficiency, transfer of samples, water volume estimation, dryweighing) is about $6 \%$ [9]. Furthermore, the uncertainty in the exact elevation $\zeta$ leads to an error in $C$ that is proportional to the vertical concentration gradient [9]. Consequently, this error will be relatively small for the suction nozzle furthest from the bed (estimated here to equal about $10 \%$ ) but can be much larger close to the bed where concentration gradients are steep (estimated 20-50\%). Note that this error also depends on the degree of bed mobility, with relatively higher values at locations with strong local bed erosion and accretion or with bed form migration.

Time-varying concentrations were measured by the ACVP through inversion of the acoustic intensity signal (see Section 2.4). The ACVP velocity and concentration measurements are collocated, allowing a direct estimation of the instantaneous sediment flux $[21,29,39]$. Additional time-varying concentration measurements were obtained at $40 \mathrm{~Hz}$ using an Optical Backscatter Sensor (OBS), which was located within the ACVP measuring range (Fig. 2). The OBS was calibrated at UPC through experiments with a replica of the apparatus described by Downing and Beach [16] using samples of the sand in the flume. The OBS data were used for validating the phase-averaged ACVP concentration.

Water surface elevations $(\eta)$ were sampled at $f_{s}=40 \mathrm{~Hz}$, using pressure transducers (PTs) and resistive (wire) wave gauges (RWGs). Bed profile measurements were obtained using echo sounders deployed from a second mobile trolley. More information about the measurement protocols and collected data can be found in van der Zanden et al. [62]).

\subsection{Measurement procedure}

One experiment consisted of six individual 15-minute runs. The bed profile was measured prior to the first run and after every 2nd run, i.e. at $t=0,30,60$ and $90 \mathrm{~min}$. After the sixth run, the flume was drained, the initial bed profile was restored, and any bed forms that were generated were flattened. The 90-minute experiment was repeated 12 times, with the mobile measuring frame moved to a new cross-shore location for each experiment, which resulted in a high spatial coverage 
of measurements (Fig. 1b). The measurement locations cover $0.9 \mathrm{~L}$, where $L$ is the measured wave length in the test section, and comprise the shoaling to inner surf zone. The high repeatability of the hydrodynamics and bed profile evolution following this procedure was demonstrated in van der Zanden et al. [62].

\subsection{Data treatment}

For each 15-minute run the first $5 \mathrm{~min}$ of data were discarded because hydrodynamic equilibrium was not yet established. Flume seiching induced a standing wave with an amplitude of $O(\mathrm{~cm})$ and a 45s period, which was removed from all water surface and velocity time series using a high-pass filter [62]. Modulations of the cross-shore wave breaking location by flume seiching are estimated to be of $O(0.1 \mathrm{~m})$, which is considered small compared to the wave length. The autospectra and autocorrelation functions of suspended sediment concentrations (OBS, ACVP) and time-varying bed levels (ACVP) did not reveal any distinct peaks at the seiching-wave frequency. This shows that flume seiching had a negligible effect on sediment transport.

The conversion of the ACVP's acoustic intensity profiles to sand concentration profiles followed the inversion method by Hurther et al. [22]. Sediment concentrations $C(\check{z})$ at vertical distance $\check{z}$ from the transmitter were calculated from the transmitter downwards while accounting for the attenuation (dominated by sand-particle scattering) of the acoustic pulses along their travel path through the water-sand mixture, as:

$$
\begin{array}{lr}
\mathrm{C}(\check{\mathrm{z}})=J(\check{\mathrm{z}}) & \text { for } \check{z}=0 \\
\mathrm{C}(\check{\mathrm{z}}+\Delta \check{z})=\mathrm{C}(\check{z}) \frac{\mathrm{J}(\check{\mathrm{z}}+\Delta \check{\mathrm{z}})}{J(\check{z})} \exp \left(\zeta_{\mathrm{s}} \mathrm{C}(\check{z}) \Delta \mathrm{r}\right) & \text { for } \check{z}+\Delta \check{z}>0 .
\end{array}
$$

where $\zeta_{s}$ is a sand attenuation parameter; $\Delta r$ is the change in pulse travel distance over a vertical displacement $\Delta \check{z}$ between two consecutive bins; $J(\check{z})$ is the normalized acoustic intensity received by the sensors, i.e.:

$J(\check{z})=\frac{I(\check{z})}{A_{\mathrm{h}, \mathrm{s}}(\check{z})}$,

where $I(\check{z})$ is the measured squared voltage amplitude output and $A_{h, s}(\check{z})$ is a depth-varying function that depends on hardware characteristics, water absorption effects and acoustic scattering characteristics of the sediment. For the present experiments, both $A_{h, s}(\check{z})$ and $\zeta_{s}$ were calibrated based on the TSS measurements in the ACVP profile, instead of using semi-empirical formulations that might be invalid for the present system characteristics and experimental conditions. Using this calibration approach, $A_{h, s}(\breve{Z})$ follows an exponentially decaying function with distance $\check{z}$ and $\zeta_{s}$ has a constant value for all experimental runs. Prior to the inversion, the output signal $I(\check{z})$ was de-spiked using a moving median filter with a window width of 5 measurements.

The local bed level, extracted from the ACVP measurements following Hurther and Thorne [21], was used to calculate the mean $\zeta$ for each instrument over a run. Instantaneous ACVP measurements were discarded when the local bed eroded beyond the ACVP profiling range or when it accreted to within $5 \mathrm{~cm}$ of the ACVP transmitter. The ACVP profiles of velocity, sand concentration, and sand fluxes were corrected for local bed evolution prior to phase-averaging by calculating $\zeta$ levels for each wave cycle [62].

Horizontal and vertical velocity $u$ and $w$ were transformed to bedparallel $u_{R}$ and bed-normal $w_{R}$ components, calculated using

$u_{R}=u \cos (\beta)+w \sin (\beta)$

$w_{R}=w \cos (\beta)-u \sin (\beta)$

where $\beta$ is the rotation angle that minimized the orbital velocity amplitude of $w_{R}$ close to the bed (at $\zeta=0.03 \mathrm{~m}$ ). In applying Eq. (3), the value for $\beta$ was determined for each individual wave cycle. The mean rotation angle for each run was found to match closely the local bed slope obtained from the bed profile measurements, which supports the validity of the transformation procedure. The velocity measurements were de-noised and decomposed into time-averaged $(\bar{u}, \bar{w})$, periodic $(\tilde{u}, \widetilde{w})$ and turbulent $\left(u^{\prime}, w^{\prime}\right)$ components; the latter component was used to quantify the turbulent kinetic energy $k$ [62]).

Velocity, concentration and sediment flux measurements were phase-averaged following procedures described in van der Zanden et al. [62]. For the locations with migrating bed forms (i.e. the inner surf zone), time intervals for phase-averaging of ACVP measurements were chosen such that exactly 1 or 2 complete bed forms were captured (i.e. ripple-averaging). The number of wave cycles for phase-averaging was about 150 for water surface and outer-flow velocity data, but somewhat lower (typically about 100, with a minimum of 40) for the ACVP measurements due to the discarding of data. Phase-averaged quantities are annotated with angle brackets and are normalized such that $t / T=0$ corresponds to maximum water surface level (wave crest) at $x=50.0 \mathrm{~m}$. Subscript $\mathrm{rms}$ is used to denote root-mean-square magnitudes of a quantity.

\section{Bed evolution and hydrodynamics}

This section discusses the bed profile evolution and the cross-shore variation in hydrodynamic parameters. A more extensive description of the measured near-bed hydrodynamics, including turbulence, can be found in van der Zanden et al. [62].

The profile development in Fig. 3a shows that the bar crest grows and migrates slightly onshore during the experiment. Net erosion occurs between $x=45$ and $51 \mathrm{~m}$, producing an onshore-directed influx of sediment at $x=51.0 \mathrm{~m}$. This leads to an increase in the bar's offshore slope from $\tan (\alpha)=0.10$ to $\tan (\alpha)=0.13$ and an increase in the surf similarity parameter $\xi_{0}$ from 0.54 to 0.68 . At the same time the bar trough deepens, resulting in a steepening of the shoreward-facing slope of the bar from $\tan (\alpha)=-0.21$ to $\tan (\alpha)=-0.48$. At $90 \mathrm{~min}$, the slope approaches the natural angle of repose $\left(\alpha=26-34^{\circ}\right)$ for sandy materials [33].

Bed forms were observed after draining the flume. The bed was flat in the shoaling region until the bar crest ( $x=48.0$ to $55.5 \mathrm{~m}$ ). Quasi-2D features (quasi-uniform in longshore direction) were identified along the shoreward-facing slope of the bar ( $x=55.5$ to $57.0 \mathrm{~m}$ ), where they migrated progressively offshore. Shoreward-facing lunate-shaped features were present at the bar trough $(x=57.0$ to $59.0 \mathrm{~m})$. In the inner surf zone, a gradual transition to quasi-2D bed features occurred (from $x=59.0$ to $62.0 \mathrm{~m}$ ). Further shoreward these features became increasingly irregular while their wave length reduced, resulting in 3D sand ripples $(x=62.0 \mathrm{~m}$ to $68.0 \mathrm{~m})$. Only in the inner surf zone $(x \geq$ $59.0 \mathrm{~m}$ ), bed form lengths were of similar magnitude as the orbital semi-excursion length $a=\sqrt{2} T \widetilde{u}_{\mathrm{R}, \mathrm{rms}} / 2 \pi$ (Table 2).

Fig. 3a shows that wave height $H$ decreases by $50 \%$ between the break point $(x=53.0 \mathrm{~m})$ and splash point $(x=59.0 \mathrm{~m})$. Time-averaged water levels $\bar{\eta}$ show set-down in the shoaling zone and set-up in the inner surf zone. Fig. $3 \mathrm{~b}$ shows the maximum offshore and onshore phase-averaged velocities in bed-parallel direction at $\zeta=\delta$, where $\delta(\approx 0.01$ to $0.02 \mathrm{~m})$ is the WBL overshoot elevation during the crest phase. The reduced wave height and the increasing water depth shoreward of the bar crest $(x=55.0$ to $57.0 \mathrm{~m}$ ) leads to a strong decrease in amplitudes of periodic velocities while the offshore-directed time-averaged velocity (undertow) increases in magnitude. Consequently, along the shoreward-facing slope of the bar $(x$ $=56.0$ to $57.5 \mathrm{~m}$ ) the near-bed velocities are directed offshore during (almost) the entire wave cycle.

Fig. 3c shows the time-averaged turbulent kinetic energy $(\bar{k})$ at outer-flow elevation $\zeta=0.38 \mathrm{~m}$ and inside the WBL $\left(k_{b}\right)$. The latter is defined as the maximum $\bar{k}$ at $\zeta \leq \delta$. Turbulence production by wave breaking leads to large magnitudes of outer-flow $\bar{k}$ in the vicinity of the plunge point at $x=55.5 \mathrm{~m}$. At most locations, $\bar{k}$ decreases towards the bed, indicating that at outer-flow elevations the dominant source of turbulence is production near the water surface due to wave breaking. Breaking-generated turbulence is advected to offshore locations while 

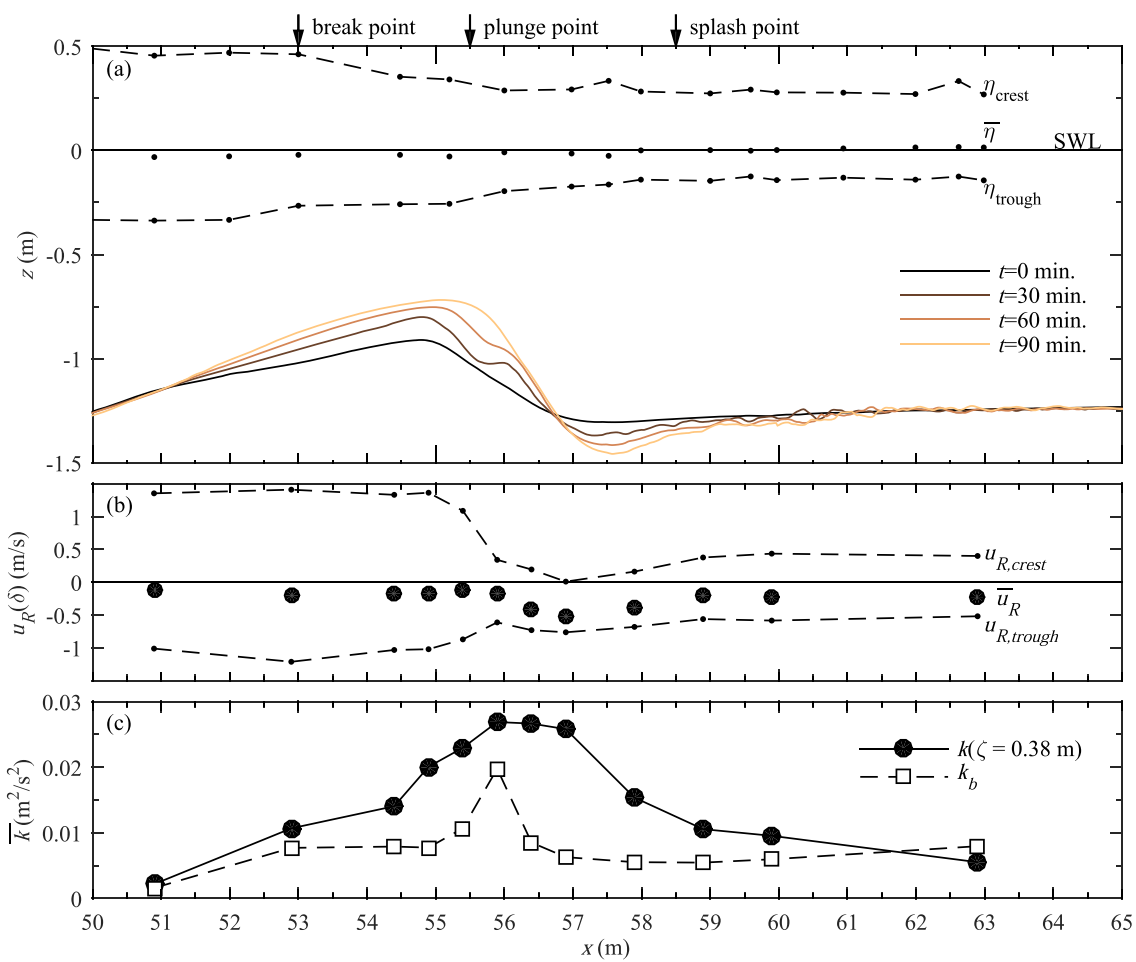

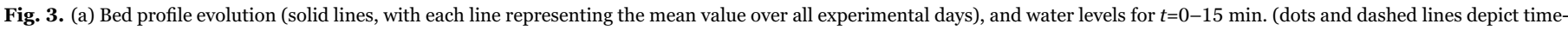

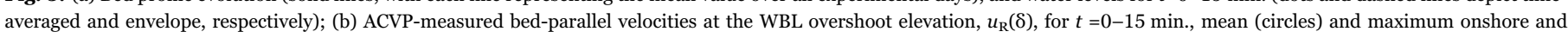

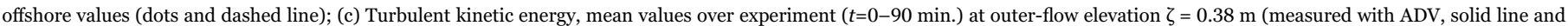
circles) and maximum time-averaged TKE inside the WBL (measured with ACVP, dashed line and squares).

gradually dissipating, leading to a decrease in TKE from the breaking zone in the offshore direction (from $x=55.5$ to $51.0 \mathrm{~m}$ ). TKE inside the WBL $\left(k_{b}\right)$ increases by an order of magnitude from the shoaling zone $(x$ $=51.0 \mathrm{~m})$ to the breaking region $(x=53.0$ to $58.0 \mathrm{~m})$. This increase occurs in spite of a reduction in peak onshore/offshore velocities, which shows that the increase is not due to turbulence production by bed shear, but instead is due to the invasion of breaking-generated TKE into the WBL. The increase in $k_{b}$ throughout the inner surf zone ( $x \geq$ $59.0 \mathrm{~m}$ ) is due an increase in bed roughness (i.e. due to bed forms) and in turbulence production at the bed.

\section{Suspended sediment transport processes}

Several definitions for bedload and suspended load can be found in the literature. From a physical perspective, bedload can be defined as the transport that is supported by intergranular forces and the suspended load as transport supported by fluid drag [4]. Others, following a more pragmatic approach, have defined bedload (suspended load) as the transport below (above) a reference elevation, i.e. the level of the bed [32] or a roughness-dependent elevation slightly above the bed $[63,64]$. In the present study, we use a wave-averaged reference elevation at $\zeta=0.005 \mathrm{~m}$ to distinguish between bedload $(\zeta<$ $0.005 \mathrm{~m})$ and suspended load $(\zeta>0.005 \mathrm{~m})$. This is based firstly on physical arguments, as bedload in the present experiment occurs partly in the sheet flow regime and sheet flow transport is usually considered part of bedload [40]. In the present study, detailed sheet flow layer measurements were obtained near the bar crest where the top of the sheet flow layer was found at $\zeta \approx 0.005 \mathrm{~m}$ ([61], Chapter 4). Secondly, although the ACVP is capable of measuring sediment fluxes in the bedload layer (e.g. [21,29]), the bedload flux estimations merit special attention in implementation of the acoustic inversion and acoustic bed interface tracking methods due to the very high vertical gradient of

Table 2

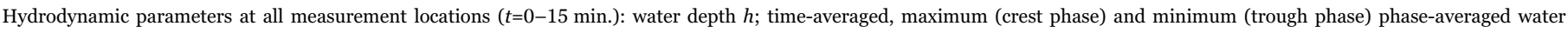

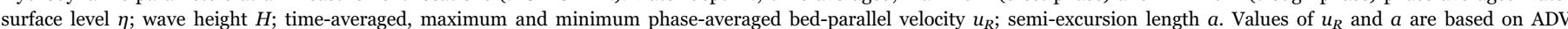
measurements at $\zeta=0.11 \mathrm{~m}$.

\begin{tabular}{|c|c|c|c|c|c|c|c|c|c|}
\hline $\begin{array}{l}x \\
(\mathrm{~m})\end{array}$ & $\begin{array}{l}h \\
(\mathbf{m})\end{array}$ & $\eta^{-}(\mathbf{m})$ & $\begin{array}{l}<\eta\rangle_{\max } \\
\text { (m) }\end{array}$ & $\begin{array}{l}<\eta\rangle_{\min } \\
\text { (m) }\end{array}$ & $\begin{array}{l}H \\
(\mathbf{m})\end{array}$ & $\begin{array}{l}\overline{\mathrm{u}}_{R} \\
(\mathbf{m} / \mathbf{s})\end{array}$ & $<u_{R}>_{\max }(\mathrm{m} / \mathrm{s})$ & $\left.<u_{R}\right\rangle_{\min }(\mathrm{m} / \mathrm{s})$ & $\begin{array}{l}a \\
(\mathrm{~m})\end{array}$ \\
\hline 51.0 & 1.10 & -0.04 & 0.45 & -0.35 & 0.79 & -0.13 & 1.04 & -0.83 & 0.54 \\
\hline 53.0 & 0.97 & -0.04 & 0.44 & -0.31 & 0.74 & -0.22 & 0.80 & -0.94 & 0.48 \\
\hline 54.5 & 0.88 & -0.05 & 0.37 & -0.26 & 0.64 & -0.19 & 0.84 & -0.85 & 0.47 \\
\hline 55.0 & 0.88 & -0.04 & 0.36 & -0.25 & 0.60 & -0.24 & 0.78 & -0.90 & 0.47 \\
\hline 55.5 & 0.97 & -0.04 & 0.29 & -0.23 & 0.51 & -0.23 & 0.57 & -0.83 & 0.39 \\
\hline 56.0 & 1.10 & -0.01 & 0.29 & -0.20 & 0.50 & -0.30 & 0.25 & -0.82 & 0.31 \\
\hline 56.5 & 1.19 & -0.04 & 0.30 & -0.22 & 0.53 & -0.51 & 0.05 & -0.83 & 0.25 \\
\hline $\mathbf{5 7 . 0}$ & 1.24 & -0.04 & 0.27 & -0.21 & 0.48 & -0.54 & 0.02 & -0.78 & 0.23 \\
\hline 58.0 & 1.28 & -0.01 & 0.30 & -0.19 & 0.47 & -0.46 & 0.01 & -0.71 & 0.21 \\
\hline 59.0 & 1.28 & -0.01 & 0.28 & -0.16 & 0.43 & -0.36 & 0.13 & -0.71 & 0.23 \\
\hline 60.0 & 1.26 & -0.01 & 0.27 & -0.15 & 0.42 & -0.36 & 0.17 & -0.66 & 0.24 \\
\hline 63.0 & 1.26 & 0.02 & 0.27 & -0.14 & 0.41 & -0.34 & 0.19 & -0.58 & 0.23 \\
\hline
\end{tabular}



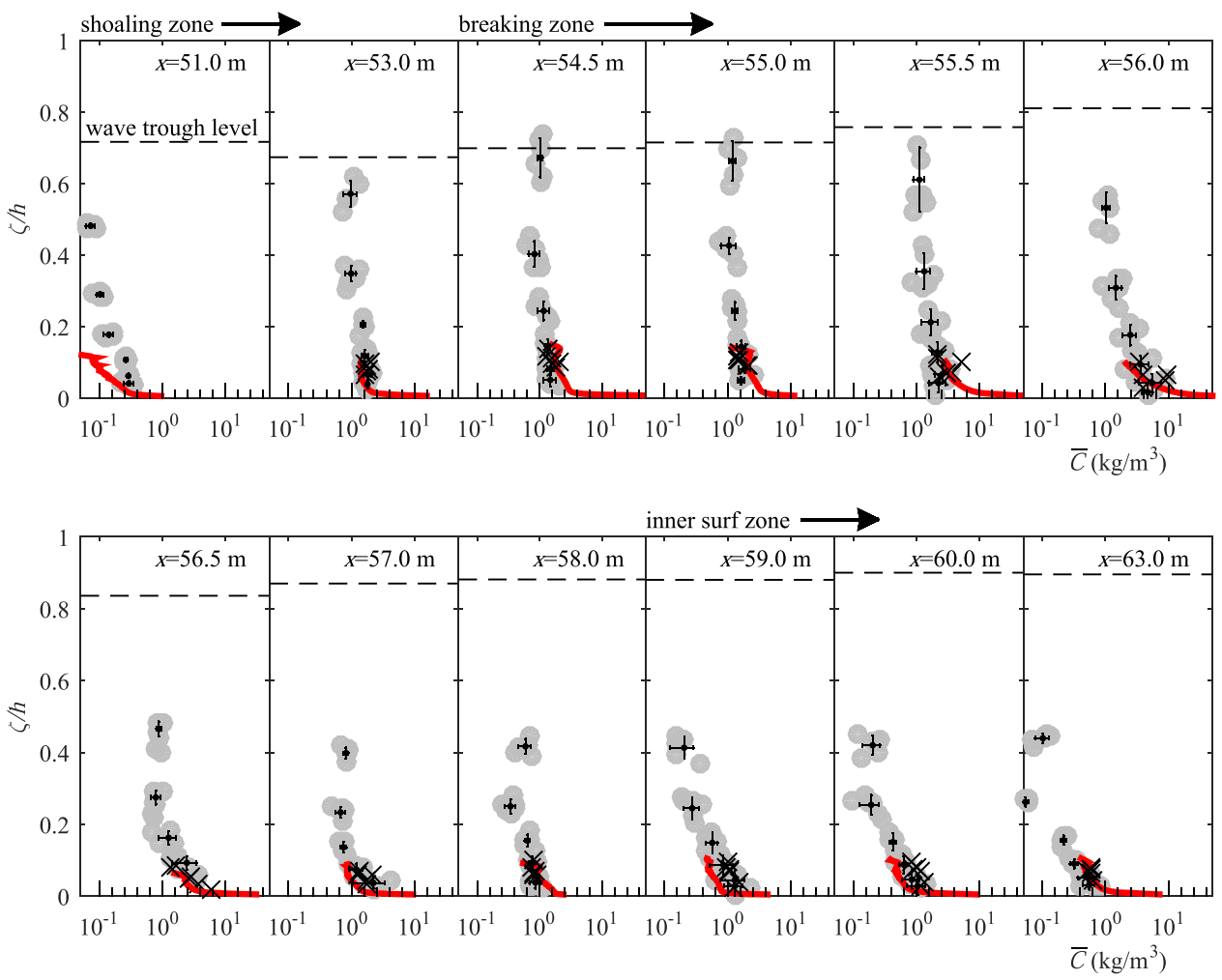

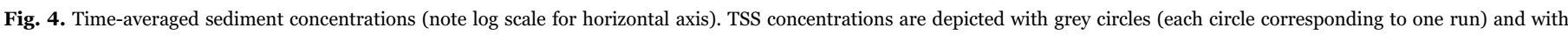

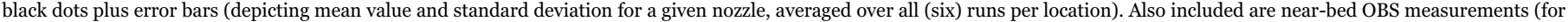

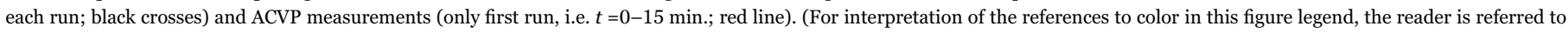
the web version of this article.)

sediment concentrations in the sheet flow layer and the strong temporal variability of the bed level at intra-wave time scale. For these reasons, bedload fluxes were not considered in the present study and it was decided to truncate the ACVP measurements for $\zeta<0.005 \mathrm{~m}$.

\subsection{Suspended sediment concentrations}

\subsubsection{Time-averaged concentrations}

Fig. 4 shows vertical profiles of time-averaged suspended sediment concentrations $\bar{C}(\zeta)$. At $x=51.0 \mathrm{~m}$, sediment concentrations were below the OBS detection limit and were therefore discarded. The different instruments (TSS, OBS, ACVP) generally yield consistent results. Comparison of the different panels reveals a strong cross-shore variation in suspended sediment concentration profiles. At all twelve locations, $\bar{C}(\zeta)$ follows a rapid decrease within the first few $\mathrm{cm}$ from the bed, and follows a more gradual decrease at outer-flow elevations. Such upward-concave profiles on log-linear scale are indicative of Rouseshaped concentration profiles, which have been observed in oscillatory flow tunnel measurements over plane-beds [41] and under small-scale laboratory breaking waves [25]. These profiles can be described with a power function:

$\bar{C}(\zeta)=C_{0}\left(z_{\mathrm{a}} / \zeta\right)^{1 / m}$

where $C_{o}$ is the time-averaged concentration at reference elevation $z_{a}$ close to the bed and $m$ is a vertical mixing parameter. Alternatively, exponential distributions for $\bar{C}(\zeta)$ have been proposed for non-breaking [32] and breaking waves [2]. In the present study, $\bar{C}(\zeta)$ follows an exponential decrease with $\zeta$ for parts of the water column, but the full profile of $\bar{C}(\zeta)$ from near-bed to water surface is better described through Eq. (4).

At $x=51.0 \mathrm{~m}$, low concentrations are found throughout the water column (of order $0.1-1 \mathrm{~kg} / \mathrm{m}^{3}$ ). Much higher concentrations are found in the breaking region at the bar crest ( $x=53.0$ to $55.5 \mathrm{~m}$ ). At these locations, $\bar{C}(\zeta)$ is almost depth-uniform and is of substantial magnitude $\left(>1 \mathrm{~kg} / \mathrm{m}^{3}\right)$ up to wave trough level. An accompanying experiment with similar bed profile and the same wave conditions [42] showed that the near depth-uniform concentration profiles above the bar crest extend up to wave crest level, yielding significant concentrations at elevations above wave trough level. Over the shoreward slope of the bar $(x=56.0$ and $56.5 \mathrm{~m}), \bar{C}(\zeta)$ shows strong depth-dependency with particularly high concentrations ( 1 to $10 \mathrm{~kg} / \mathrm{m}^{3}$ ) in the lower half of the water column. Over the bar trough $(x=57.0$ to $58.0 \mathrm{~m})$ sediment concentrations are much lower than over the bar crest. In the inner surf zone ( $x=59.0$ to $63.0 \mathrm{~m}$ ), $\bar{C}(\zeta)$ exponentially decreases between $\zeta=$ 0.02 and $0.3 \mathrm{~m}$ (i.e. a straight line in $\log$ scale). This is consistent with previous observations over rippled beds (e.g. [32]) and suggests that ripple vortex suspension controls $\bar{C}(\zeta)$ in the lower $0.3 \mathrm{~m}$. At higher elevations $\bar{C}(\zeta)$ tends to a more depth-uniform distribution, which may relate either to enhanced mixing by breaking-generated TKE in the higher part of the water column or to arrival of horizontally advected suspended sediment.

The reference concentration $C_{0}$ and vertical mixing parameter $m$ (Eq. (4)) are important parameters in suspended sediment transport modeling. These parameters are therefore quantified by log-fitting Eq. (4) through the ACVP-measured $\bar{C}(\zeta)$ between $\zeta=z_{a}$ and $0.10 \mathrm{~m}$, using a reference elevation $z_{a}=0.005 \mathrm{~m}$ for the time-averaged $C_{0}$. The crossshore distribution of both parameters is presented in Fig. 5 .

Fig. 5 a shows the mixing parameter $m$. Strong mixing (i.e. high $m$ ) occurs above the bar crest ( $x=53.0$ to $55.0 \mathrm{~m}$ ) and can be explained by the presence of breaking-generated turbulence (c.f. Fig. 3c). In addition, at these locations, the time-averaged vertical velocity $\bar{w}$ directs upwards due to a two-dimensional $(u, w)$ time-averaged fluid circulation cell in the breaking region. The presence of this 2-D circulation follows from the strong cross-shore gradients in the bed-parallel undertow velocity $\left(\mathrm{d} \bar{u}_{R} / \mathrm{d} x\right)$ : mass conservation requires these gradients to be balanced by a significant bed-normal velocity component. 

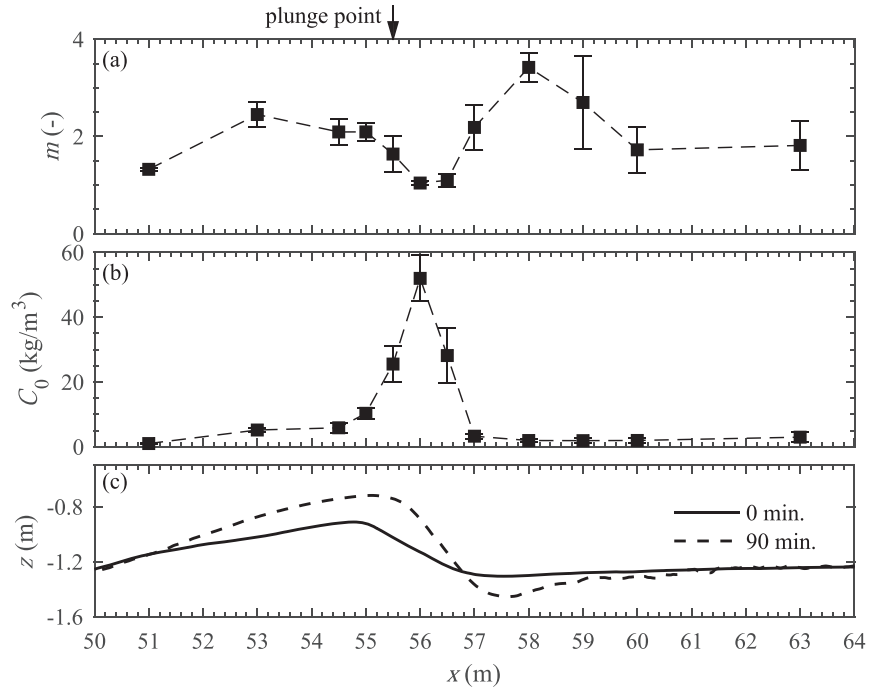

Fig. 5. Cross-shore distribution of (a) vertical mixing parameter and (b) time-averaged reference concentration; mean values (squares) and 95\% confidence intervals (error bars) over six runs per location. (c) Bed profile at 0 and $90 \mathrm{~min}$.

Above the bar crest at $\zeta=0.10 \mathrm{~m}$, measured $\bar{w}_{R}$ reaches values up to $0.05 \mathrm{~m} / \mathrm{s}$, i.e. twice the sediment settling velocity $w_{s}$.

High $m$ is also found above the bar trough (around $x=58.0 \mathrm{~m}$ ). However, for the present strongly non-uniform conditions, the suspended sediment profile $\bar{C}(\zeta)$ may not be fully explained by local vertical sediment mixing and settling. As will be shown in Section 4.2.2, sediment is advected high in the water column from the breaking region to the inner surf zone, leading to a positive net influx of horizontally advected sediment above the bar trough that may contribute to the near depth-uniform $\bar{C}(\zeta)$ around $x=58.0 \mathrm{~m}$.

Relatively low $m$ occurs along the shoreward-facing bar slope $(x=$ 55.5 to $57.0 \mathrm{~m}$; Fig. 5a), despite highest TKE at these locations (c.f. Fig. 3c). At these locations, high reference concentrations suggest that sediment pick-up rates are high (Fig. 5b). We anticipate that the crossshore advection rate of the entrained particles, due to the strong undertow, exceeds the vertical turbulent mixing rate, leading to a relatively steep vertically decreasing $\bar{C}(\zeta)$ profile.

Fig. $5 \mathrm{~b}$ shows the reference concentration which varies by an order of magnitude along the test section. $C_{0}$ is highest along the shorewardfacing bar slope at $x=56.0 \mathrm{~m}$, slightly shoreward from the plunge point. Empirical predictions of $C_{0}$ are commonly based on the waveplus current-induced bed shear stress $([32,64])$. To assess the predictive capability of the wave-induced velocity in terms of $C_{0}$, Fig. 6 a shows a scatter plot of $C_{0}$ versus rms near-bed orbital velocity. Distinction is made between the region up to the plunge point above the bar crest $(x<55.5 \mathrm{~m})$, the breaking region along the shorewardfacing bar slope and bar trough $(55.5 \leq x<59.0 \mathrm{~m})$ and the inner surf zone $(x \geq 59.0 \mathrm{~m})$. The figure reveals no clear relation between the two parameters and linear regression between $C_{0}$ and $\tilde{u}_{\text {rms }}$ revealed no significant correlation (significance level $P<0.05$ ). In addition, $C_{0}$ did not correlate significantly with estimates of wave- plus current-induced bed shear stress (obtained following [40]) nor with the Sleath parameter that is a measure of horizontal pressure gradient induced sediment mobilization [18]. Note that the poor correlation between $C_{0}$ and $\tilde{u}_{\text {rms }}$ is particularly caused by the high $C_{0}$ values in the breaking region between $x=55.5$ and $57.0 \mathrm{~m}$. When these points are omitted, $C_{0}$ does correlate significantly with $\tilde{u}_{\text {rms }}$, as is to be expected from previous observations under non-breaking waves.

Previous studies revealed that breaking-induced turbulence may promote instantaneous bed shear stresses [12,71] and can induce upward-directed pressure gradients in the bed [53]. Therefore, to assess whether breaking-induced turbulence affects the entrainment of sand particles in the present study, Fig. $6 \mathrm{~b}$ shows a scatter plot of $C_{0}$
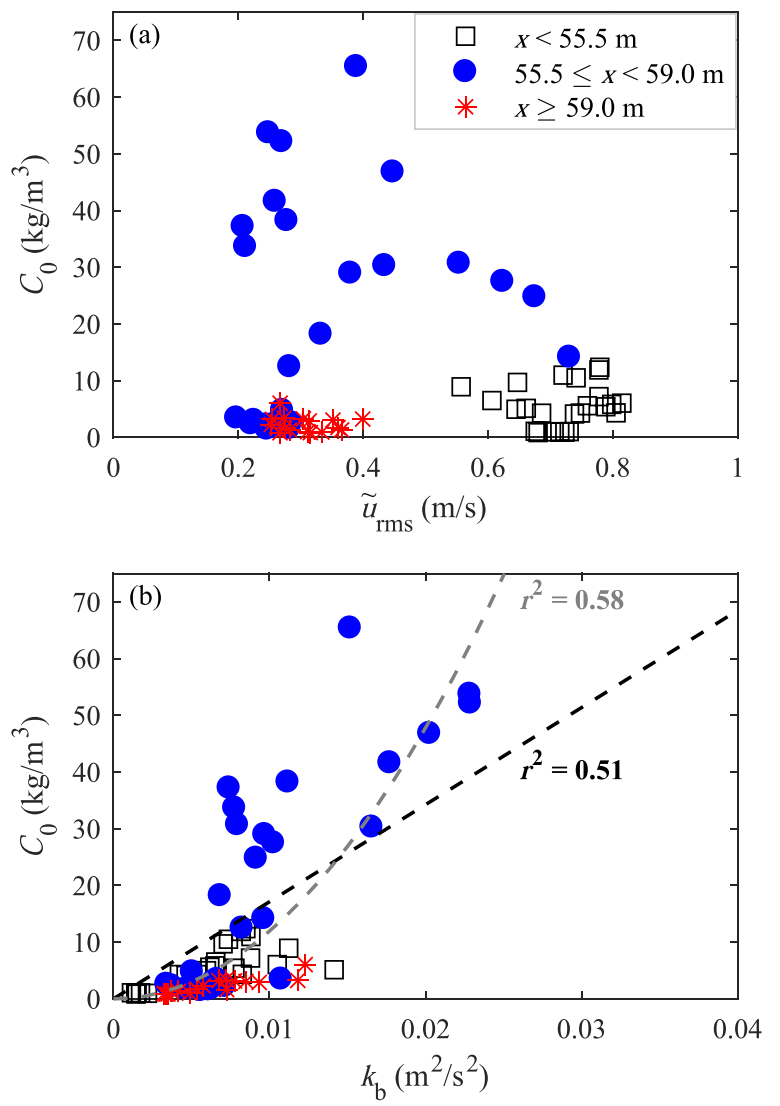

Fig. 6. Scatter plots of the time-averaged reference concentration $C_{0}$ versus (a) rootmean-square orbital velocities at $\zeta=\delta$ and (b) maximum time-averaged TKE in the WBL, $k_{\mathrm{b}}$. Each measurement point corresponds to a 15 -minute run. Distinction is made between measurements from the shoaling and breaking region up to bar crest (squares), the breaking region over the shoreward bar slope and bar trough (circles) and the inner surf zone (asterisks). In panel (b), the black dashed line corresponds to a linear relation $C_{0}=1.7 \cdot 10^{3} \cdot k_{\mathrm{b}}$ while the grey dashed line denotes a quadratic relation $C_{0}=1.2 \cdot 10^{5} \cdot \mathrm{k}_{\mathrm{b}}{ }^{2}$.

versus the maximum time-averaged TKE in the WBL, $k_{b}$. The figure shows that $C_{0}$ correlates positively with $k_{b}$; the correlation is significant based on a linear regression $(P<0.05)$. For purely bed-generated turbulence, $k_{b}$ would be related to $\tilde{u}_{\mathrm{rms}}^{2}$, hence these results suggest that external breaking-generated TKE that invades the WBL is an important driver for sediment entrainment. This result is consistent with previous observations of wave breaking turbulence effects on sediment pick-up $[28,31,48,53]$.

\subsubsection{Time-varying concentrations}

The physical relation between hydrodynamic forcing and sediment concentration can be explored in more detail through the phaseaveraged time series. Fig. 7 shows ACVP-measured concentrations < $C(\zeta, t)>$ in the near-bed layer from $\zeta=0.005 \mathrm{~m}$ to $0.10 \mathrm{~m}$. The figure includes the phase-averaged bed-parallel velocities $\left\langle u_{R}\right\rangle$ and nearbed TKE $\left\langle k_{n b}\right\rangle$ for reference purposes. The overshoot elevation $\delta$ during the crest phase is included as a proxy for the WBL thickness. The figure also shows depth-averaged concentrations $\left(C_{n b}\right)$ over the near-bed layer between $\zeta=0.005 \mathrm{~m}$ and $0.10 \mathrm{~m}$. The $C_{n b}$ values were normalized by their time-averaged equivalent to illustrate the relative temporal variation in the near-bed suspended load.

Consistent with results in the previous section, the color contours in Fig. 7 reveal strong spatial (both horizontally and vertically) variation in concentration. The temporal variation in concentration appears more limited. This holds particularly for elevations above the WBL and at locations far from the breaking point (e.g. $x=51.0 \mathrm{~m}$ and $59.0-$ $63.0 \mathrm{~m}$ ). The temporal variation was quantified by computing the normalized coefficients of variation $\left(\langle C\rangle_{r m s} / \bar{C}\right)$, yielding typical 

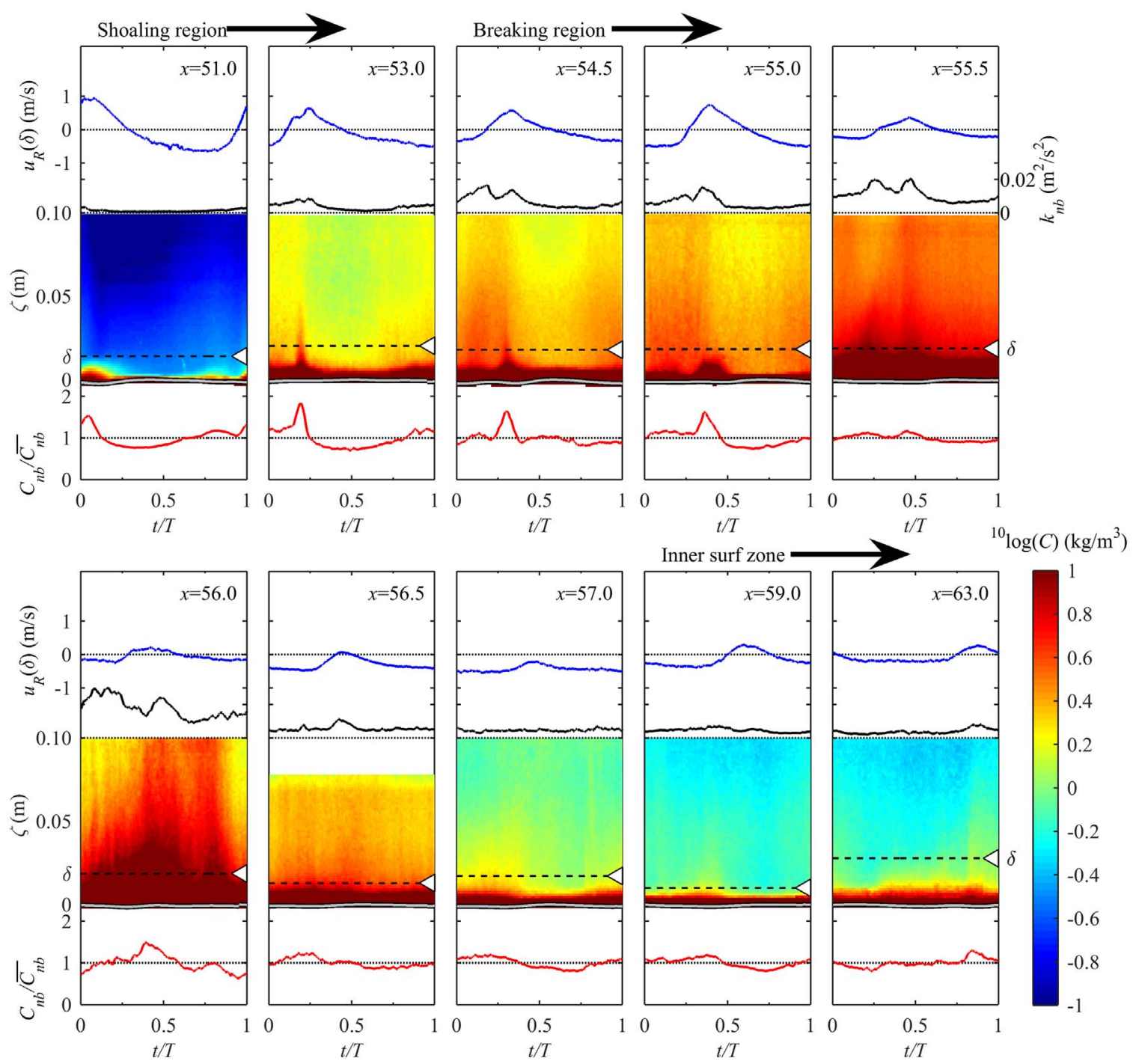

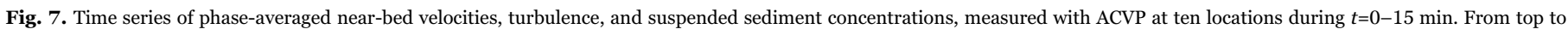

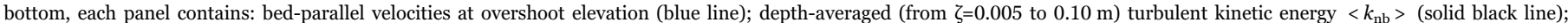

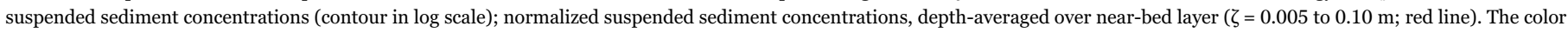

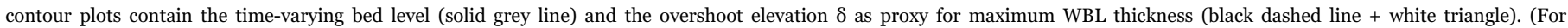
interpretation of the references to color in this figure legend, the reader is referred to the web version of this article.)

values of about $10 \%$ above the WBL, but much larger values (50-80\%) inside the WBL. Apparently, the temporal variation in phase-averaged sediment concentration is mostly restricted to the WBL, whereas outerflow concentrations are fairly constant throughout the wave cycle. This WBL and outer-flow behavior is consistent with earlier observations under non-breaking waves (e.g. [47]), but it differs from earlier studies that reported significant intra-wave variation in outer-flow suspended sediment concentration under plunging waves [10,2]. Section 5 (Discussion) further addresses these differences.

The shoaling locations $(x=51.0-55.0 \mathrm{~m})$ consistently reveal a distinct short-duration peak of increased sediment concentrations inside the WBL, which occurs between the moment of offshore-toonshore flow reversal and the moment of maximum $\langle u\rangle$ during the crest phase. This can be explained by local sediment entrainment during instances of maximum flow velocity; the suspension events lead the maximum free-stream onshore/offshore $\langle u\rangle$ because of the WBL phase lead. Additional processes contributing to high concentrations during the crest phase are the accumulation of sediment under the wave front by the convergence of horizontally advected sediment [26], and the vertical sediment advection by upward periodic velocities during the trough-to-crest flow reversal [14]. At outer-flow elevations $(\zeta>\delta), C$ increases gradually during the wave trough phase (e.g. at $x=$ $54.5 \mathrm{~m}$ from $t / T \approx 0.7$ ) and decreases during the crest phase (e.g. at $x=$ $54.5 \mathrm{~m}$ from $t / T \approx 0.3$ ).

In the breaking region $(x=55.0-59.0 \mathrm{~m})$ the temporal variation in $\langle C\rangle$ is relatively small. Close to the plunge point $(x=55.5-$ $56.0 \mathrm{~m}$ ), highest concentrations are found at around the passing of the wave crest. Further shoreward $(x=56.5-59.0 \mathrm{~m})$, concentrations are highest during the trough phase when highest near-bed velocity magnitudes are reached. Further into the inner surf zone (at $x=$ $63.0 \mathrm{~m}$ ) concentrations are slightly higher during the crest phase than during the trough phase. In this rippled bed region, it is likely that vortex formation contributes to the higher concentrations at the wave crest phase [21,59].

At most locations, $\left\langle C_{n b}\right\rangle$ is roughly phase-coherent with $\left\langle k_{n b}\right\rangle$. This is consistent with previous studies showing phase-coherency between near-bed $C$ and $k$ under breaking waves $[10,69]$. It was shown that $\left\langle k_{n b}\right\rangle$ for the present experiment is not only explained by local processes, i.e. production at the bed or near the water surface and vertical advection/diffusion, but that it is also affected by horizontal advection [62]. Similarly, we may expect $\left\langle C_{n b}\right\rangle$ to be affected by a combination of local vertical processes and horizontal advection. Both 
contributions are quantified in Section 4.3.

\subsection{Cross-shore sediment flux}

This section analyses the flux components contributing to the total net suspended sediment transport. Section 4.2.1 analyses the near-bed flux, while Section 4.2.2 analyzes the flux over the whole water column.

\subsubsection{Near-bed flux}

Local horizontal sediment fluxes $\Phi_{x}$ are the product of velocity $u$ and concentration $C$ and are decomposed in the same way as velocities, i.e. through a Reynolds decomposition [62], into:

$\bar{\Phi}_{x}=\overline{u C}=\bar{u} \bar{C}+\overline{\widetilde{u} \widetilde{C}}+\overline{u^{\prime} C^{\prime}}=\bar{\phi}_{x}+\widetilde{\phi}_{x}+\phi^{\prime}{ }_{x}$.

Here, $\bar{\phi}_{x}$ (current-related), $\widetilde{\phi}_{x}$ (wave-related) and $\phi^{\prime}{ }_{x}$ (turbulent) represent the three components of the total time-averaged horizontal sediment flux $\bar{\Phi}_{x}$. The co-located ACVP measurements of velocities and sediment concentration enable quantification of all fluxes in Eq. 5, including the turbulent diffusive flux $\phi$ ' (see e.g. [30]). In the present experiment the turbulent flux was truncated for frequencies higher than $7 \mathrm{~Hz}$ to eliminate contributions by incoherent scattering to timeaveraged $\phi$ ' (see [56]).
Fig. 8 (color contours) shows phase-averaged sediment fluxes $<\Phi_{x}$ $>$ in the bed-parallel direction. Highest (onshore/offshore) flux magnitudes occur between $x=53.0$ and $56.0 \mathrm{~m}$. Flux magnitudes decrease rapidly with distance from the bed, with fluxes outside the WBL up to an order of magnitude lower than fluxes inside the WBL.

Fig. 8 further shows the time-averaged bed-parallel fluxes $\bar{\Phi}_{x}$ and the contributions of each transport component indicated in Eq. (5) (2nd and 4th row of panels). At most locations, the vertical profile of $\bar{\Phi}_{x}$ shows a sharp transition around $\zeta=\delta$, with much higher $\bar{\Phi}_{x}$ inside the WBL $(\zeta<\delta)$ than at outer-flow elevations $(\zeta>\delta)$. At shoaling and breaking locations before the bar crest $(x=51.0-55.0 \mathrm{~m})$, wave-related fluxes $\widetilde{\phi}_{x}$ inside the WBL are directed onshore. This is explained by two processes. Firstly, the velocity- and acceleration-skewed oscillatory flow leads to higher bed shear during the crest phase and the quasiinstantaneous response of medium-sediment transport leads to an onshore wave-related suspension flux in the WBL (e.g. [47]). Secondly, the free-surface effect leads to upward sediment advection during the wave upward zero crossing, leading to stretching of the concentration profile under the crest and compression during the trough phase which also results in a net onshore-directed wave-related flux in the WBL $[14,26]$. Current-related fluxes $\bar{\phi}_{x}$ inside the WBL at shoaling locations are offshore-directed due to the undertow. The onshore-directed wave-
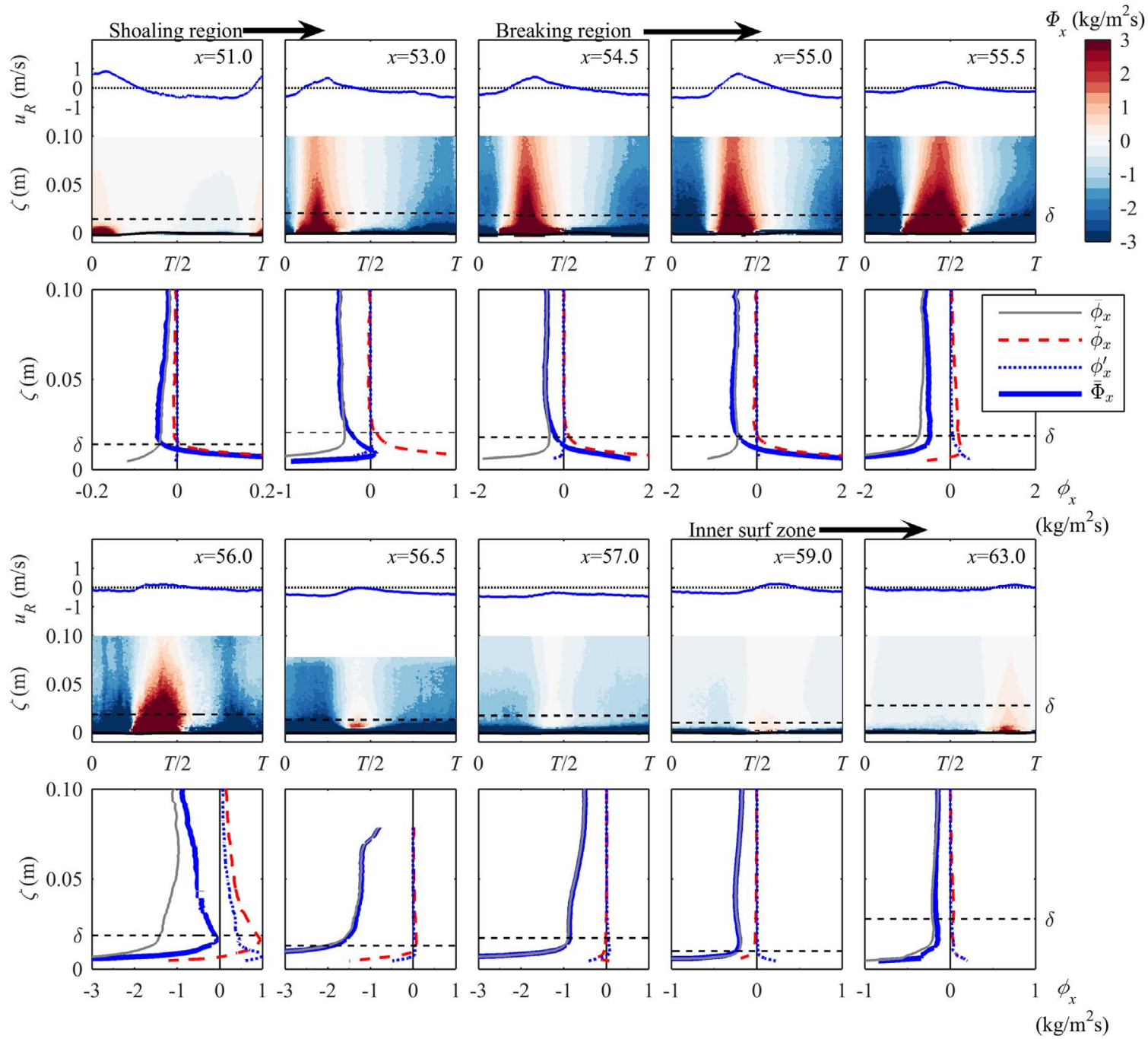

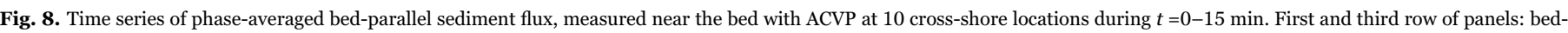

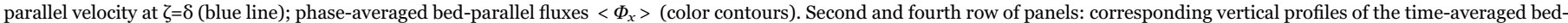

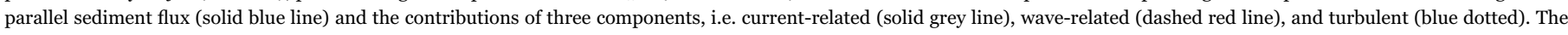

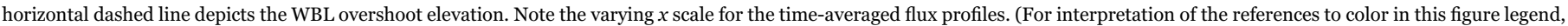
the reader is referred to the web version of this article.) 
related fluxes balance (at $x=53.0 \mathrm{~m}$ ) or exceed $(x=51.0,54.5,55.0 \mathrm{~m})$ the offshore current-related fluxes inside the WBL. Above the WBL, the net flux $\bar{\Phi}_{x}$ is dominated by the current-related component. Although temporal variation in sediment concentrations exists above the WBL, it does not result in a significant contribution to the time-averaged waverelated fluxes at $x=51.0-55.0 \mathrm{~m}$. The different flux behavior inside and above the WBL yields a transition from onshore-directed $\Phi_{x}$ for $\zeta$ $<\delta$ to offshore-directed $\bar{\Phi}_{x}$ for $\zeta>\delta$.

In the breaking zone, the total net flux $\bar{\Phi}_{x}$ at all elevations is dominated by the current-related contribution. Significant contributions of $\widetilde{\phi}_{x}$ and $\bar{\phi}_{x}$ occur at $x=56.0 \mathrm{~m}$ at both WBL and outer-flow elevations. Note that this is the location that is most directly influenced by breakinginduced TKE (Fig. 3c). In addition, note that in the breaking region the periodic velocity $\tilde{u}$ and the wave-related flux $\widetilde{\phi}_{x}=\tilde{u} \widetilde{C}$ are not purely driven by the irrotational wave motion but may also contain contributions by the rotational phase-coherent vortex motion. The wave-related fluxes at this location are directed onshore as the crest-phase concentrations exceed the concentrations during the trough phase. The onshore-directed $\widetilde{\phi}_{x}$ counterbalances about $30 \%$ of the offshore-directed $\bar{\phi}_{x}$ (depth-averaged over $\zeta$ $=\delta$ to $0.10 \mathrm{~m}) . \widetilde{\phi}_{x}$ declines much more rapidly than $\bar{\phi}_{x}$ with distance from the bed. Consequently, at $\zeta=0.10 \mathrm{~m}$, the wave-related flux is minor $(<$ $10 \%)$ compared to the current-related flux.

In the inner surf zone, $\bar{\Phi}_{\mathrm{x}}$ is dominated by the current-related flux $\bar{\phi}_{x}$, which can be attributed to the strong undertow. The wave-related flux remains negligibly small, despite the presence of orbital sand ripples for which significant wave-related flux contributions to total net transport have been measured for oscillatory conditions without a freestream mean (undertow) current (c.f. [60]).

Evident contributions by the diffusive flux $\bar{\phi}$, ${ }_{x}$ only occur at $x=$ $56.0 \mathrm{~m}$, where it declines rapidly with distance from the bed and is negligible outside the near-bed region $(\zeta>0.10 \mathrm{~m})$. Magnitudes of $\bar{\phi}_{x}{ }_{x}$ reach up to $1 \mathrm{~kg} / \mathrm{m}^{2} \mathrm{~s}$, which is small compared to $\bar{\phi}_{x}$ and $\widetilde{\phi}_{x}$ at this location, but is nevertheless considerable compared to flux magnitudes at other cross-shore locations. Therefore, the time-dependent $\phi_{x}^{\prime}$ is explored in more detail through Fig. 9, which as an example shows a short interval of time series at $x=56.0 \mathrm{~m}$. Note that the bed gradually erodes during the selected time interval.

Fig. 9c shows the instantaneous sediment concentration, revealing multiple suspension events that are to some extent phase-coherent, with a stronger presence during time instants of maximum offshore or onshore velocity, but are also partly random, i.e. the events may occur during any instance of the wave cycle and show strong wave-to-wave variability. Inter-comparison with Fig. $9 \mathrm{~b}$ reveals that some - but not all - suspension events coincide with events of high near-bed TKE (e.g. events II and III indicated by the arrows). This is consistent with previous observations and numerical simulations of intermittent TKE and sediment suspension under breaking waves [48,69,71].

The coherency between TKE and suspension events does not directly drive a net flux as TKE is a scalar quantity with no direction. Instead, $\bar{\phi}_{x}{ }_{x}$ is the net horizontal diffusive flux by the (breakinggenerated) turbulent structures in the direction of lowest concentration. This diffusive flux is typically modelled as (e.g. [64]):

$\overline{\phi^{\prime}}{ }_{\mathrm{x}}=\overline{u^{\prime} C^{\prime}}=-\overline{\varepsilon_{s}} \frac{\mathrm{d} \bar{C}}{\mathrm{~d} x}$,

where $\varepsilon_{\mathrm{s}}$ is the horizontal sediment diffusivity which scales with the turbulent diffusivity of the fluid. The high turbulence levels at $x=$ $56.0 \mathrm{~m}$ likely promote high $\varepsilon_{\mathrm{s}}$. The net diffusive flux $\bar{\phi}_{x}{ }_{x}$ at $x=56.0 \mathrm{~m}$ is onshore, consistent with Eq. 6 and with the positive concentration gradient $-\mathrm{d} C / \mathrm{d} x>0$ (c.f. Fig. 7 ).

Fig. 9 indicates examples of energetic turbulent events (arrows in panel b) that contribute to onshore $\bar{\phi}{ }_{x}$. Turbulent event I drives offshore diffusion of fluid parcels with low concentration $\left(u^{\prime}<0, C^{\prime}<0\right)$, while events II and III are responsible for onshore diffusion of highconcentration fluid $\left(u^{\prime}>0, C^{\prime}>0\right.$ ) (Fig. 9a and Fig. 9c). All three events contribute to net onshore diffusion $\phi_{x}^{\prime}=u^{\prime} C^{\prime}>0$ (Fig. 9d).

Sand fluxes in bed-normal direction, $w_{R} C$, appeared to be highly sensitive to uncertainties in the applied rotation angle $\beta$ in Eq. (3) and were therefore not examined in detail.

\subsubsection{Flux over whole water column}

The depth-integrated, time-averaged suspended transport rate $q_{s}$ is

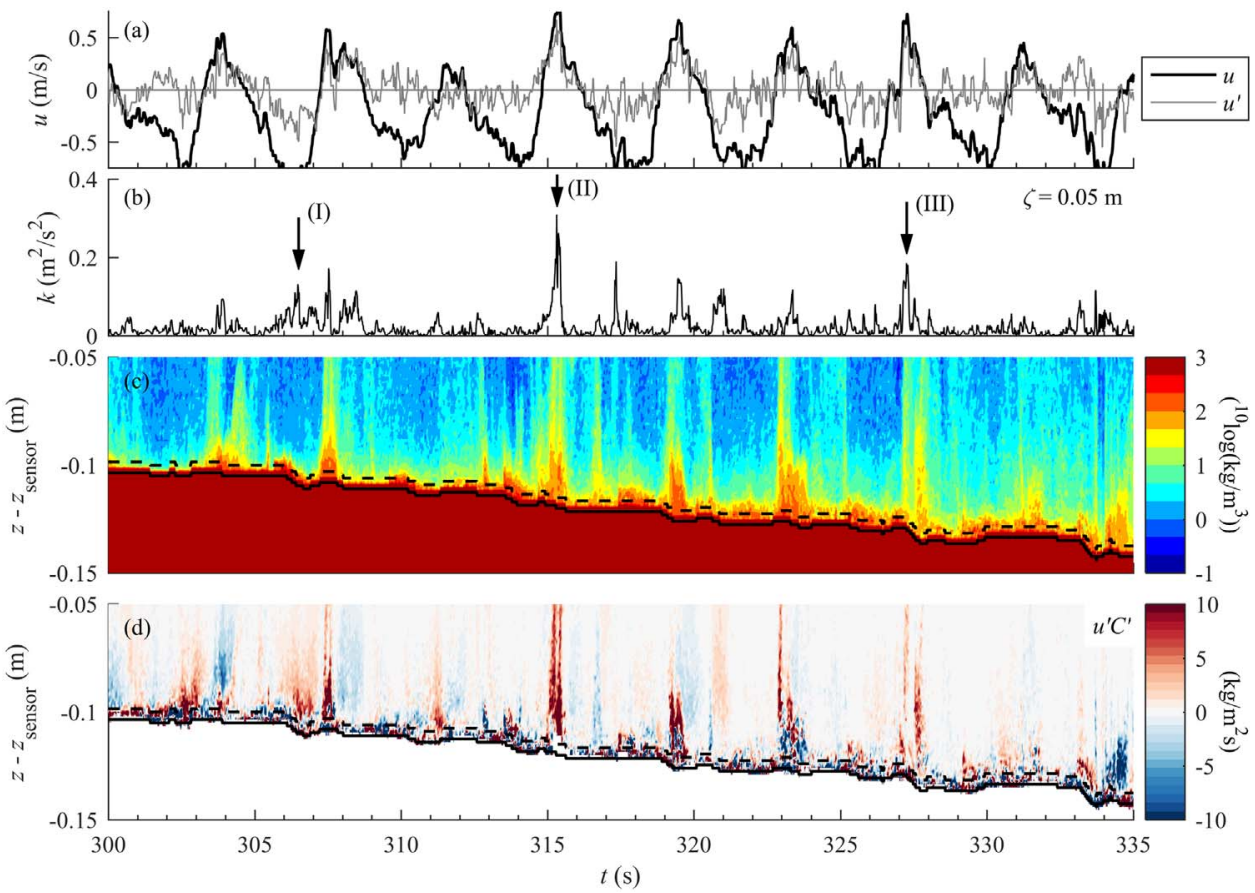

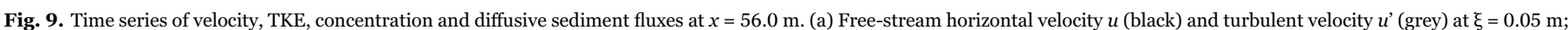

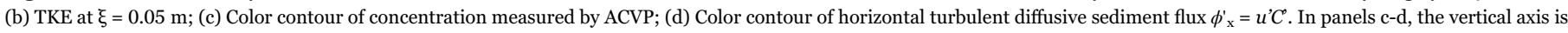

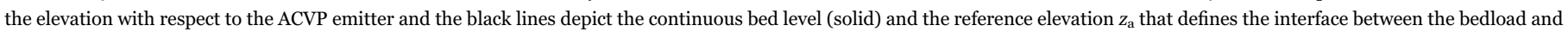
suspended load layers (dashed). 

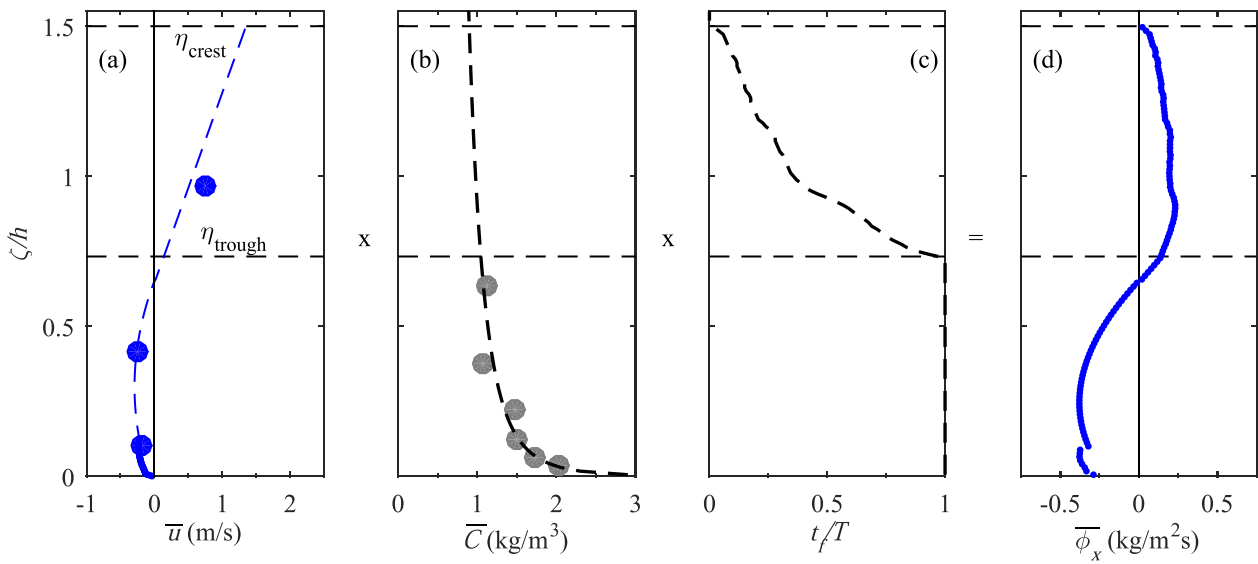

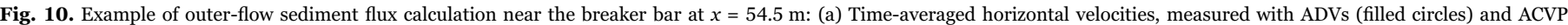

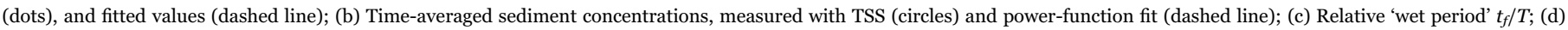
Current-related sediment flux profile $\bar{\phi}_{x}(\zeta)$, as the product of the dashed lines in panels a-c.

given by

$q_{\mathrm{s}}=q_{\mathrm{s}, \mathrm{wbl}}+q_{\mathrm{s}, \text { outer }}=\int_{z_{\mathrm{a}}}^{\delta} \bar{u} \bar{C} \mathrm{~d} \zeta+\int_{\delta}^{\eta_{\text {crest }}} \bar{u} \bar{C} \frac{t_{f}}{T} \mathrm{~d} \zeta$,

where $q_{s, w b l}$ is the net transport rate inside the WBL; $q_{s, \text { outer }}$ is the net transport rate over the outer flow; $z_{a}=0.005 \mathrm{~m}$ is the elevation taken to separate suspended and bed load; $\delta$ is the WBL overshoot elevation $(\approx 0.02 \mathrm{~m}) ; \eta_{\text {crest }}$ is the wave crest level; and the parameter $t_{f} / T$ is the relative 'wet period', i.e. the fraction of the wave cycle for which an elevation is immersed. Note that $\bar{u}$ in Eq. (7) is defined as the timeaveraged horizontal velocity over the wet period and not over the full wave cycle. The ACVP-measured fluxes allow direct computation of
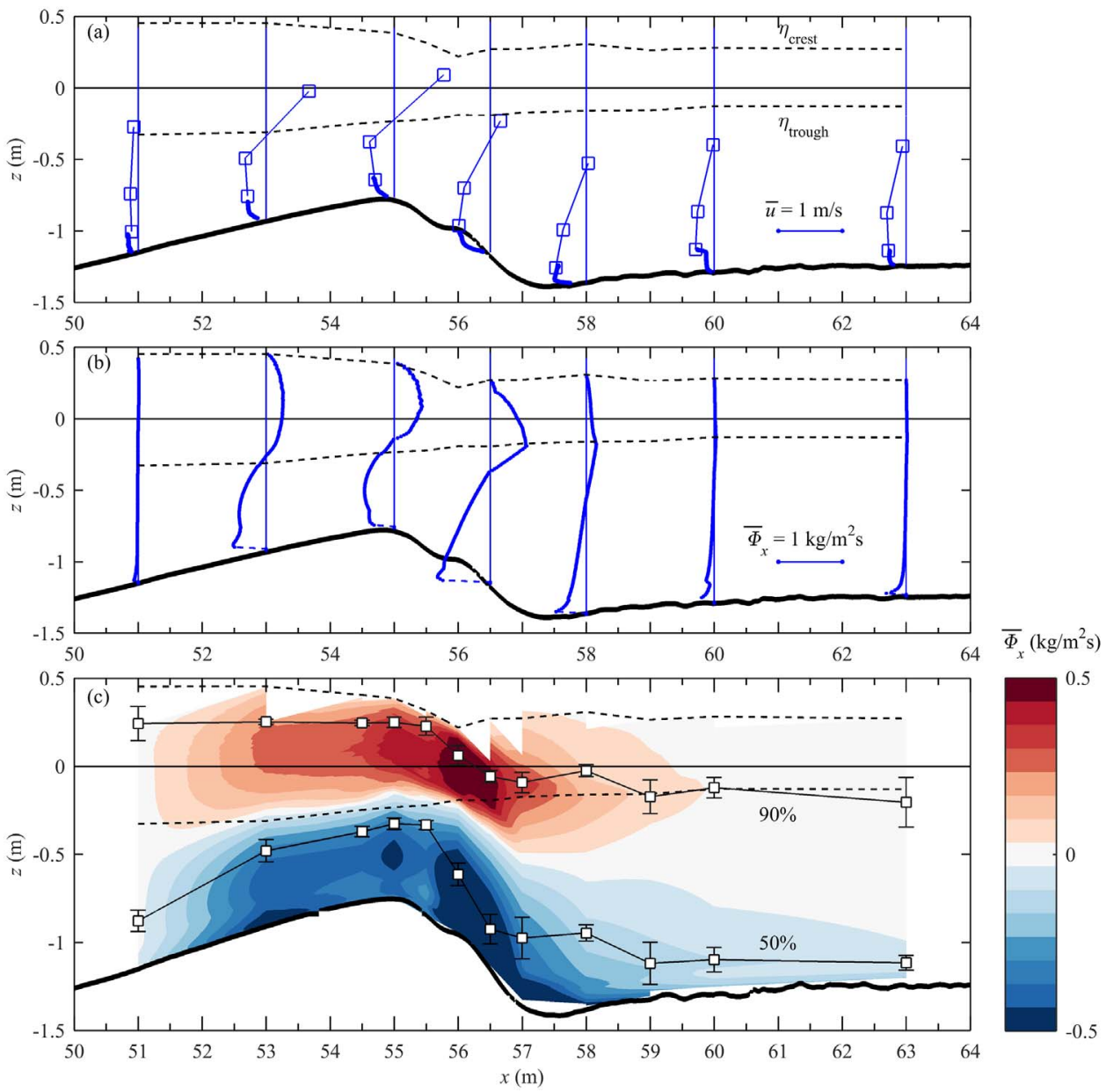

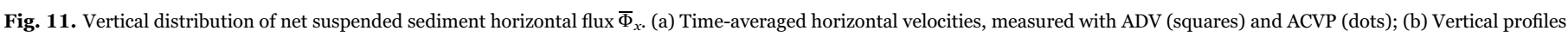

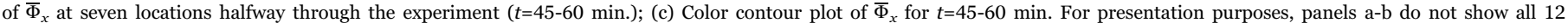

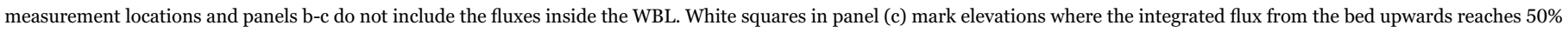

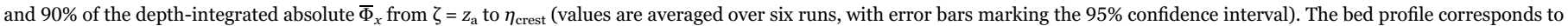
$t=45 \mathrm{~min}$. 
$q_{s, w b l}$. In the previous section it was shown that outer-flow fluxes are dominated by the current-related contribution, i.e. $\bar{\Phi}_{x} \approx \bar{\phi}_{x}$ for $\zeta>\delta$. Therefore, to compute $q_{s, \text { outer }}$, the profile of horizontal fluxes over the complete water column was estimated by vertical inter- and extrapolation of time-averaged velocities and concentrations (illustrated in Fig. 10).

Fig. 10a shows an example of measured and fitted $\bar{u}(\zeta)$. Profiles of $\bar{u}(\zeta)$ were based on a combination of ACVP measurements (for $\delta<\zeta<$ $0.10 \mathrm{~m}$ ) and a semi-empirical fit through ADV measurements (for $\zeta>$ $0.10 \mathrm{~m}$ ). For $0.10 \mathrm{~m}<\zeta<\eta_{\text {trough }}$, the profile was approximated with a parabolic distribution following undertow approximations by Kobayashi et al. [25]. At elevations above wave trough level, $\bar{u}(\zeta)$ was approximated through a linear increase with a slope that was chosen such that the time-averaged depth-integrated mass balance is zero $\left(\int_{0}^{\eta_{\text {crest }}} \bar{u} t_{f} / T \mathrm{~d} \zeta=0\right)$. Note that other distributions of $\bar{u}(\zeta)$ for $\zeta>\eta_{\text {trough }}$ (e.g. exponential or quadratic increase) did not result in large differences in the depth-integrated suspended transport, because $\bar{C}(\zeta)$ is nearly depth-uniform for $\zeta>\eta_{\text {trough }}$. The profile of suspended sediment concentrations $\bar{C}(\zeta)$ in the outer flow was estimated by fitting a Rouse profile (Eq. 4) through the TSS measurements (Fig. 10b). Eq. (4) was log-fitted instead of linearly fitted to reduce a bias towards high concentrations near the bed. The extrapolation of $\bar{C}$ to $\zeta>\eta_{\text {trough }}$ seems justified based on an accompanying experiment [42] which included TSS measurements between wave trough and crest level. The relative wet period $t_{f} / T$ was extracted from PT-measured water surface levels (Fig. 10c). The product of these three terms yields the time-averaged $\bar{\phi}_{x}$ profile (Fig. 10d), used for the estimation of $q_{s, \text { outer }}$ in Eq. (7).

Fig. 11b shows the resulting vertical profiles of the approximated net suspended sediment flux $\left(\bar{\Phi}_{x}\right)$ at seven cross-shore locations. Fig. 11c shows the spatial flux distribution and includes the elevations below which $50 \%$ and $90 \%$ of the flux is found. These levels are based on the depth-integrated absolute values of the flux $\int_{z_{\mathrm{a}}}^{\eta_{\text {crest }}}|\bar{\Phi} x| \mathrm{d} \zeta$ over the complete water column, including contributions by the sediment flux inside the WBL. Note that the fluxes $\bar{\Phi}_{x}$ inside the WBL (Fig. 8) are significantly higher than the outer-flow fluxes. Hence, for presentation purposes, the WBL fluxes are omitted in Fig. 11b-c. Fig. 11a shows the undertow profiles for reference.

At $x=51.0 \mathrm{~m}, \bar{\Phi}_{x}$ is much lower at outer-flow elevations than inside the WBL. In the breaking region at the bar crest ( $x=53.0-55.5 \mathrm{~m}$ ), i.e. between break point and plunge point, significant $\bar{\Phi}_{x}$ contributions to $q_{s}$ occur between wave trough and wave crest level. This is attributed to strong vertical mixing of suspended sediment in combination with relatively shallow water depths. At these locations the onshore-directed fluxes between $\eta_{\text {trough }}$ and $\eta_{\text {crest }}$ counterbalance a large portion (about $70 \%$ ) of the offshore-directed flux below wave trough level. The highest offshore-directed fluxes are found along the shoreward-facing bar slope $(x=55.5-57.0 \mathrm{~m})$ in the lower $0.2 \mathrm{~m}$ above the bed. This relates to the combination of high near-bed concentrations and the shape of the undertow profile, with strong offshore-directed $\bar{u}$ (up to $-0.8 \mathrm{~m} / \mathrm{s}$ ) close to the bed (Fig. 11a). Because the undertow follows the bed profile, it also has a strong vertical component at these locations. With $\bar{w}$ reaching values of 0.1 to $0.3 \mathrm{~m} / \mathrm{s}$, i.e. exceeding the sediment settling velocity by an order of magnitude, the undertow is highly effective in transporting suspended grains upward. Along the bar trough and inner surf zone $(x>57.0 \mathrm{~m})$, fluxes within $0.3 \mathrm{~m}$ from the bed are the main ( $>50 \%$ ) contributors to $q_{s}$ while fluxes above trough level are minor ( $<10 \%$ of $q_{s}$ ).

The vertical distribution of sediment flux is examined further in Fig. 12a, which shows the depth-integrated net suspended transport rate within the WBL $\left(q_{s, w b l}\right)$ and over the outer flow $\left(q_{s, \text { outer }}\right)$ following Eq. (7) along the bed profile. The relative importance of $q_{s, w b l}$ and $q_{s, \text { outer }}$ to total suspended transport is quantified by relative fractions $f_{w b l}$ and $f_{\text {outer }}$, based on the sum of the absolute values of both contributions (i.e. $f_{w b l}=\left|q_{w b l}\right| /\left(\left|q_{w b l}\right|+\left|q_{\text {outer }}\right|\right)$ and $\left.f_{\text {outer }}=1-f_{w b l}\right)$. Fig. $12 \mathrm{~b}$ shows the cross-shore variation in these relative fractions.
The magnitude of $q_{s, \text { outer }}$ increases strongly from $x=51.0$ to $53.0 \mathrm{~m}$, due to increasing concentrations and undertow magnitudes (Fig. 12a). Between $x=53.0$ and $55.5 \mathrm{~m}, q_{s, \text { outer }}$ remains roughly constant which is partly due to the increasing significance of transport for $\zeta>\eta_{\text {trough }}$. Along the shoreward-facing bar slope $(x=56.0-57.5 \mathrm{~m})$, $q_{s, \text { outer }}$ magnitudes increase rapidly due to the large offshore-directed fluxes close to the bed. $q_{s, \text { outer }}$ magnitudes decrease gradually along the inner surf zone as suspended sediment concentrations decrease.

The suspended transport inside the WBL $\left(q_{s, w b l}\right)$ is onshoredirected in the shoaling zone and in the breaking region up to the bar crest $(x=51.0-55.0 \mathrm{~m})$, indicating that onshore wave-related transport contributions generally exceed the offshore-directed currentrelated transport inside the WBL. The relative contribution of $q_{s, w b l}$ to total suspended transport at shoaling locations is about $10-20 \%$ (Fig. 12b). Note that $q_{s, w b l}$ is formed by two transport components of similar magnitude but with opposite sign, which partly explains why $f_{w b l}$ is small. Both $q_{s, w b l}$ and $f_{w b l}$ increase gradually from the shoaling zone to the bar crest, with maximum onshore transport found at the bar crest $(x=55.0 \mathrm{~m})$. In the breaking region along the shoreward slope of the bar $(x=55.5-57.0 \mathrm{~m}), q_{s, w b l}$ becomes offshore-directed and its magnitude increases. Also the fraction of transport confined to the WBL increases slightly, with an $f_{w b l}$ of about $20-30 \%$. At the bar trough and inner surf zone $(x=58.0-63.0 \mathrm{~m}),\left|q_{s, w b l}\right|$ decreases and the total suspended transport is largely ( $>80-90 \%$ ) determined by the outer-flow transport.

\subsection{Cross-shore advection, pick-up, and deposition}

The flux measurements presented earlier are used in this section to study the cross-shore advection of sediment in relation to the vertical sediment exchange between the suspension and bedload layer (pickup/deposition) at a wave-averaged time scale (Section 4.3.2) and at an intra-wave time scale (Section 4.3.3).

\subsubsection{Calculations}

We introduce a sediment mass balance for a control near the bed (Fig. 13), given by

$\int_{z_{\mathrm{a}}}^{D} \frac{\partial<C(\zeta, t)>}{\partial t} \mathrm{~d} \zeta+\int_{z_{a}}^{D} \frac{\partial<\Phi_{x}(\zeta, t)>}{\partial x} \mathrm{~d} \zeta+\int_{z_{\mathrm{a}}}^{D} \frac{\partial<\Phi_{z}(\zeta, t)>}{\partial z} \mathrm{~d} \zeta=0$,

where $\left\langle\Phi_{x}\right\rangle$ and $\left\langle\Phi_{z}\right\rangle$ are the phase-averaged ACVP-measured total fluxes in the horizontal and vertical direction, respectively. The control volume extends vertically from $\zeta=z_{a}=0.005 \mathrm{~m}$ up to $\zeta=D=$ $0.10 \mathrm{~m}$ and matches the near-bed layer covered by the ACVP. It follows from Eq. (8) that local concentration changes (term 1) are the result of horizontal gradients in cross-shore sediment flux, i.e. horizontal sediment advection (term 2), and of vertical gradients in the vertical sediment flux (term 3).

Equation (8) was evaluated at each cross-shore location using a central-difference scheme in both time and space, with a time step $\Delta t$ equal to $0.05 \mathrm{~s}$ and spatial step size $\Delta x$ equal to the distance between adjacent measurement locations (i.e. $0.5 \mathrm{~m}$ in the breaking zone and up to $3 \mathrm{~m}$ in the inner surf zone, c.f. Table 2). Concentrations and vertical fluxes are weighted averages of measurements at the $x$ location of interest and at the onshore and offshore adjacent locations. The horizontal gradient in sediment flux is calculated over location $x$ using $\left\langle\Phi_{x}\right\rangle$ measurements at the two adjacent locations. $\Delta x$ is of similar magnitude as the semi-excursion length $a$ and much smaller than the wave length $L(\approx 15 \mathrm{~m})$. It is therefore considered sufficient small to estimate the horizontal flux gradients with appropriate accuracy. Nevertheless, it is acknowledged that the finite number of cross-shore measurement locations leads to smoothing of the actual gradients in flux. The horizontal flux gradient cannot be estimated for the furthest offshore and onshore locations. For these locations we assume negligible contribution by horizontal advection because of the 

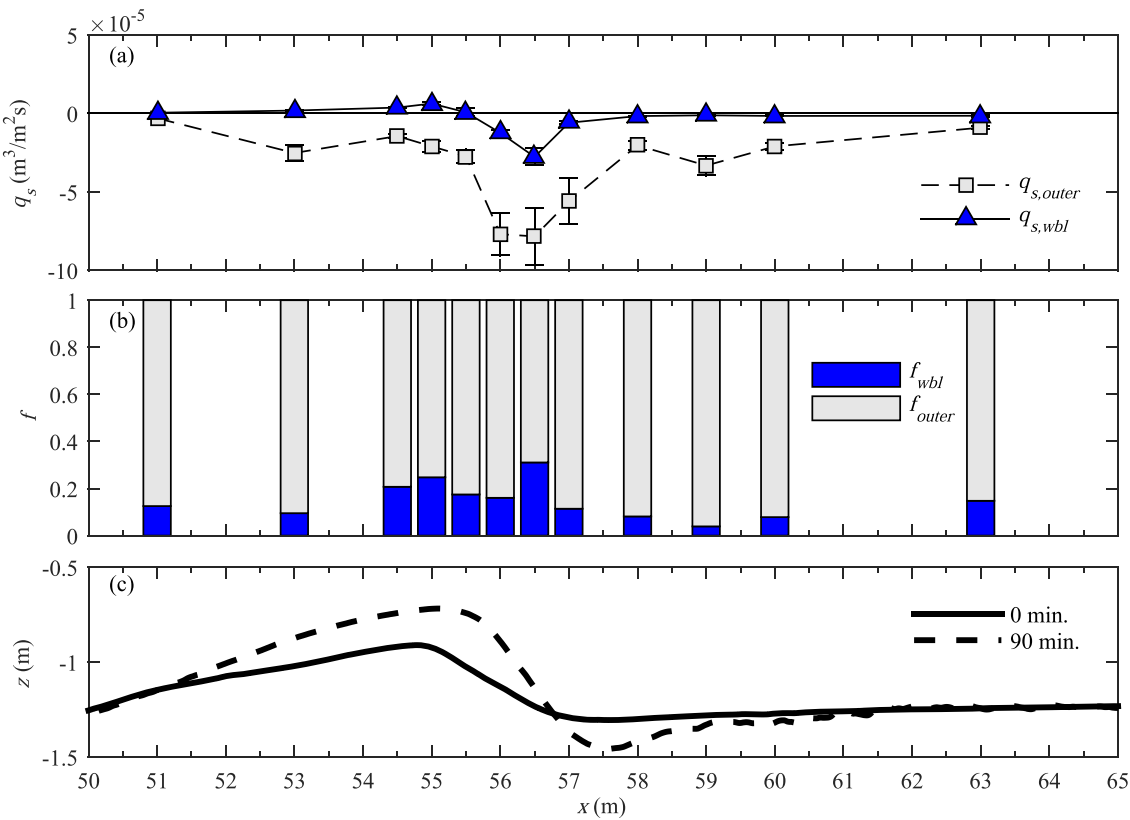

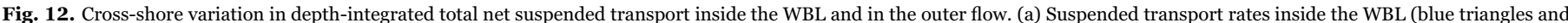

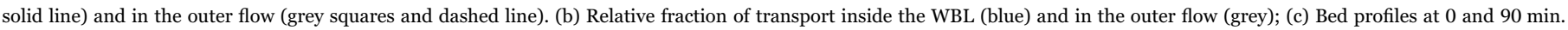

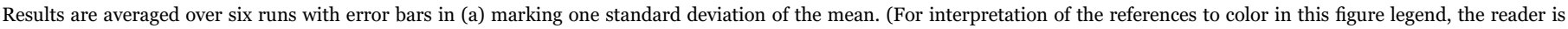
referred to the web version of this article.)

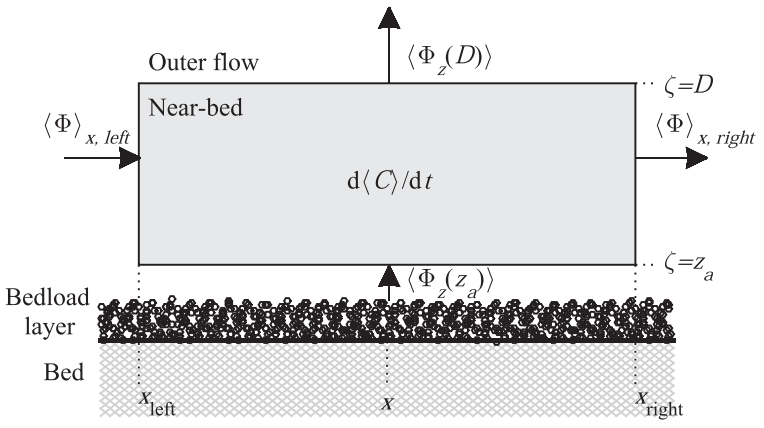

Fig. 13. Definition sketch of control volume and fluxes. The control volume extends vertically from $z_{\mathrm{a}}(=0.005 \mathrm{~m})$ to $D(=0.10 \mathrm{~m})$.

low cross-shore gradients in suspended sediment concentration and in $q_{s}$ compared to the strongly non-uniform concentrations and transport rates in the breaking region.

The depth-integrated vertical gradient in vertical flux (term 3 in Eq. (8)) equals the difference between the vertical flux at the bottom of the control volume $\left\langle\Phi_{z}\left(z_{a}\right)\right\rangle$ and the flux at the top $\left\langle\Phi_{z}(D)\right\rangle$. However, the vertical velocities very close to the bed were not properly resolved by the ACVP [62], leading to errors in $\left\langle\Phi_{z}\left(z_{a}\right)\right\rangle$. Therefore, an alternative approach was adopted as follows. The first two terms of Eq. (8) were determined from the data and the third term then follows from the mass balance. This term can be rewritten as

$\int_{z \mathrm{a}}^{D} \frac{\partial<\Phi_{z}(\zeta, t)>}{\partial z} \mathrm{~d} \zeta=\left\langle\Phi_{z}(D)>-<\Phi_{z}\left(z_{\mathrm{a}}\right)>\right.$,

which, in combination with measured $\left\langle\Phi_{z}(D)\right\rangle$, allows $\left\langle\Phi_{z}\left(z_{a}\right)\right\rangle$ to be solved. $\Phi_{z}\left(z_{a}\right)$ is the vertical exchange between the bedload layer $\left(\zeta<z_{a}\right)$ and the suspension layer $\left(\zeta>z_{a}\right)$. It can be decomposed into a deposition rate $d$ (defined positively downward) and a pick-up rate $p$ (defined positively upward). Under an assumption of free settling, which seems appropriate for medium-grained particles at concentrations of $O(1-10)$ $\mathrm{kg} / \mathrm{m}^{3}$ (e.g. [5]), the deposition rate was modeled as $d=w_{s} C\left(z_{a}\right)$ [33]. The pick-up rate is then given by $p=d+\Phi_{z}\left(z_{\mathrm{a}}\right)$. Because $p$ and $d$ were not directly measured and are based on a modeling assumption for the deposition rate, estimations of $p$ and $d$ following the above approach should be interpreted with caution. For this reason they are evaluated at a wave-averaged time scale only in what follows, i.e.:

$\bar{\Phi}_{z}\left(z_{\mathrm{a}}\right)=\bar{p}-\bar{d}=\bar{p}-w_{\mathrm{s}} \bar{C}\left(z_{\mathrm{a}}\right)$.

\subsubsection{Time-averaged pick-up, deposition and horizontal gradients in cross-shore transport}

At a wave-averaged time scale, the vertical flux between the bedload and suspension layer $\bar{\Phi}_{z}\left(z_{\mathrm{a}}\right)$ should equal the cross-shore gradient in suspended transport rate, i.e.

$\Phi_{z}\left(z_{\mathrm{a}}\right)=\frac{\mathrm{d} q_{\mathrm{s}}}{\mathrm{d} x}$,

where $q_{s}$ is the net total transport rate over the complete water column up to wave crest level (Eq. 7). Fig. 14a shows both terms of Eq. (11), with $\bar{\Phi}_{z}\left(z_{\mathrm{a}}\right)$ obtained using Eq. (9) time-averaged. Although the approaches for the two quantities are subjected to different assumptions in data treatment, the validity of both approaches (Eq. 7 and Eq. 9) is supported by the consistent results in terms of magnitude and cross-shore behavior.

$\bar{\Phi}_{z}\left(z_{\mathrm{a}}\right)$ can be interpreted as the contribution of suspended transport to the time rate of morphological change of the bar, with $\bar{\Phi}_{z}\left(z_{\mathrm{a}}\right)<0$ (net downward flux) corresponding to local accretion and $\bar{\Phi}_{z}\left(z_{\mathrm{a}}\right)>0$ to erosion. If $\bar{\Phi}_{z}\left(z_{\mathrm{a}}\right)=0$, there is no cross-shore gradient in suspended transport and time-averaged local pick-up balances deposition. The highest magnitudes of $\Phi_{z}\left(z_{\mathrm{a}}\right)$ occur between $x=54.0$ and $58.0 \mathrm{~m}$ (Fig. 14a). This relates directly to the strongly non-uniform hydrodynamics in cross-shore direction due to wave breaking and due to cross-shore-varying water depths, which lead to steep cross-shore gradients in suspended sediment concentrations and suspended transport rates. Net suspended sediment pick-up $\left(\bar{\Phi}_{z}\left(z_{\mathrm{a}}\right)>0\right)$ occurs at the shoreward slope of the bar and over the bar trough $(x=56.5-58.0 \mathrm{~m})$ while net sediment deposition $\left(\Phi_{z}\left(z_{\mathrm{a}}\right)<0\right)$ occurs around the bar crest $(x=53.0-56.0 \mathrm{~m})$. Between these regions, the undertow drives net offshore advection of suspended sediment from the bar trough to the bar crest. Note that the regions of net pick-up and net deposition are roughly consistent with net erosion and accretion regions of the bed profile (Fig. 14d). However, the profile evolution can only be fully explained by also considering the gradients in bedload transport 

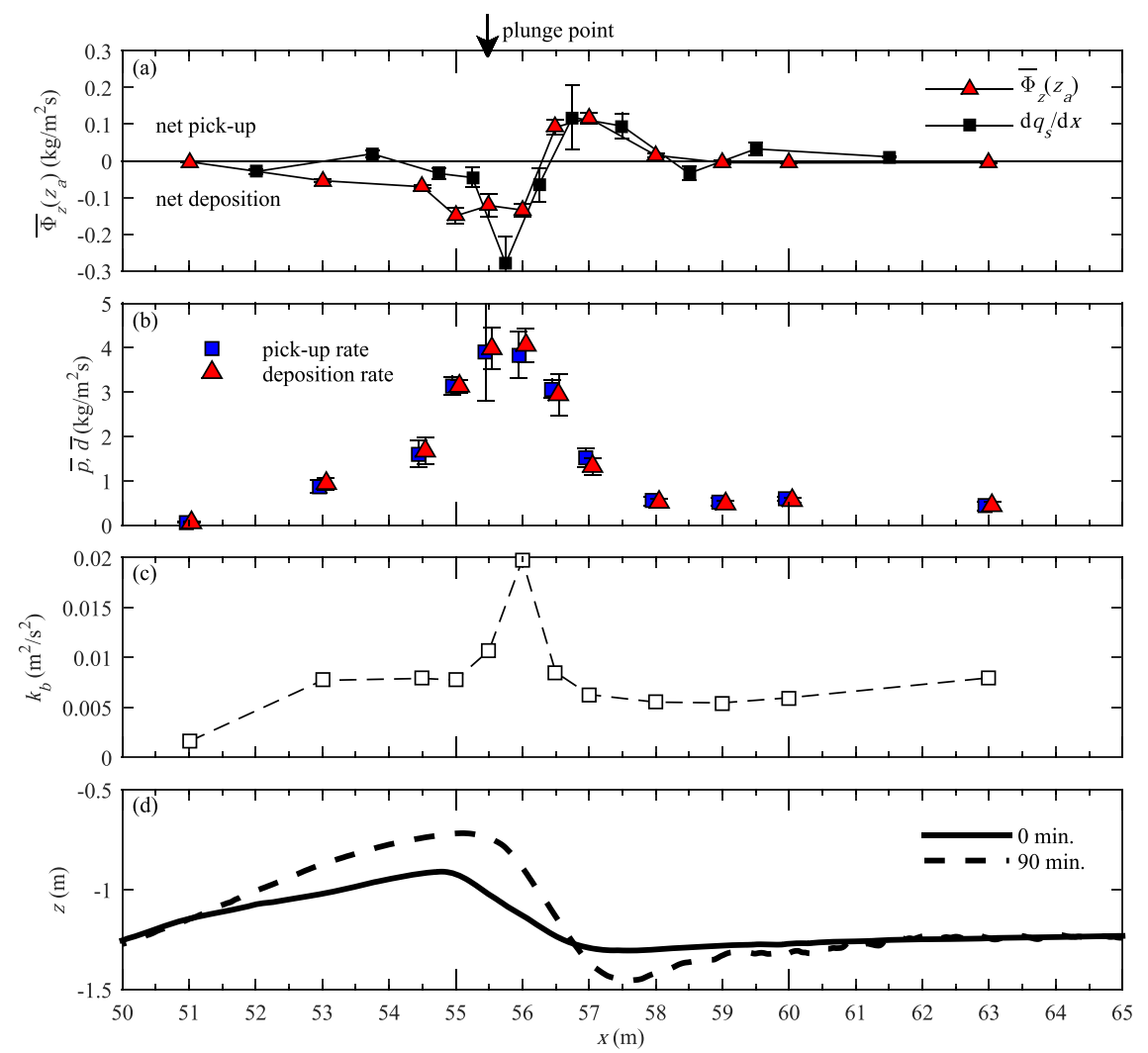

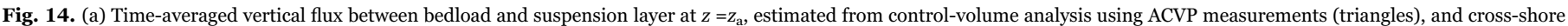

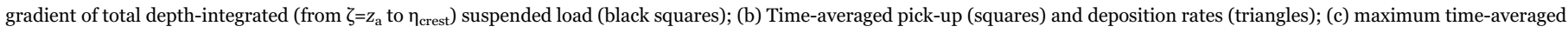

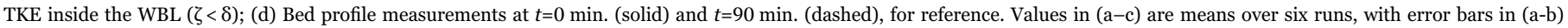
marking standard deviation of mean.

(covered in [61], Chapter 4).

Fig. 14b shows the time-averaged pick-up $(\bar{p})$ and deposition $(\bar{d})$ rates, obtained through decomposition of $\bar{\Phi}_{z}\left(z_{\mathrm{a}}\right)$ through Eq. (10). The high pick-up rates in the vicinity of the plunge point (between bar crest and bar trough) are prominent, with values that are two to five times the pick-up rates in the shoaling zone. The cross-shore variation in pick-up (Fig. 14b) does not match the cross-shore variation in maximum onshore/offshore velocities, which decrease in the breaking region (Fig. 3b). The pick-up variation shows a better similarity with the cross-shore variation in near-bed TKE (Fig. 14c), which is consistent with the results for reference concentrations discussed earlier (Section 4.1.1).

Sediment deposition and pick-up rates are of similar magnitude at all locations. The small difference between $\bar{p}$ and $\bar{d}$, i.e. the net vertical flux $\bar{\Phi}_{z}\left(z_{\mathrm{a}}\right)$, is due to the influx of horizontally-advected sediment. The contribution by horizontal sediment influx to local $\bar{d}$ is rather weak, i.e. typically less than $10 \%$, compared to contributions by locally entrained sediment given by $\bar{p}$. From this it follows that the time-averaged local deposition rate, and consequently the reference concentration $C_{0}=\bar{C}\left(z_{a}\right)$, is largely controlled by local pick-up.

\subsubsection{Horizontal advection and vertical flux contributions to intra-} wave concentration changes

The time-varying concentration behavior in the near-bed region, presented earlier in Fig. 7, can be explained in terms of cross-shore and vertical fluxes by solving Eq. (8) at an intra-wave time scale. For convenience, Eq. (8) is rewritten as:

$\frac{\partial<m_{\mathrm{nb}}>}{\partial t}=-\frac{\partial<q_{\mathrm{nb}}>}{\partial x}+<\Phi_{z}\left(z_{\mathrm{a}}\right)>-<\Phi_{z}(D)>$.

Here, $m_{n b}$ is the depth-integrated suspended sediment load over the control volume, i.e. $m_{n b}=\int_{z_{\mathrm{a}}}^{D} C \mathrm{~d} \zeta=C_{n b} .\left(D-z_{a}\right) ; q_{n b}$ is the time- varying depth-averaged horizontal suspended transport rate over $\zeta=z_{a}$ to $D ; \Phi_{z}\left(z_{a}\right)$ is the vertical flux at $\zeta=z_{a}$ and $\Phi_{z}\left(z_{a}\right)$ is the vertical flux at $\zeta$ $=D$. Because of the strong decrease in concentration with distance from the bed, the magnitudes of intra-wave $\left\langle\Phi_{z}\left(z_{a}\right)>\right.$ exceed $<\Phi_{z}(D)$ $>$ with a factor 5 to 10 (i.e. $\left.\left|\Phi\left(z_{a}\right)\right|>>|\Phi(D)|\right)$. This allows Eq. (12) to be rewritten as:

$\frac{\partial<m_{\mathrm{nb}}>}{\partial t} \approx-\frac{\partial<q_{\mathrm{nb}}>}{\partial x}+<\Phi_{z}\left(z_{\mathrm{a}}\right)>=\Delta q_{\mathrm{nb}}+<\Phi_{z}\left(z_{\mathrm{a}}\right)>$.

The flux gradient $\Delta \mathrm{q}_{\mathrm{nb}}$ is termed the horizontal influx. Note that $\Delta q_{n b}$ is defined as the negative cross-shore gradient in near-bed suspended transport rate $q_{n b}$, i.e. positive $\Delta q_{n b}$ corresponds to an increase in the suspended load $m_{n b}$. Eq. (13) states that temporal changes in the near-bed suspended load are primarily caused by horizontal sediment advection and by vertical exchange between the bedload layer and suspension layer. The vertical influx at $\zeta=D$ has minor effect on $m_{n b}$ at an intra-wave time scale and is not considered in the following analysis of $\partial<m_{n b}>/ \partial t$.

The spatio-temporal distribution of near-bed sediment concentration is examined through Fig. 15. Panel a shows the spatio-temporal variation in the depth-integrated mass $\left\langle m_{n b}\right\rangle$ over the near-bed layer (panel c) and its time rate of change $\partial<m_{n b}>/ \partial t$ (panel d), which relates to the horizontal influx $\Delta q_{n b}$ (panel e) and the vertical influx $\Phi_{z}\left(z_{a}\right)$ (panel f) following Eq. (13). For reference, the figure includes the phase-averaged bed-parallel velocities (panel a) and the freestream $\mathrm{ADV}$-measured TKE at $\zeta=0.11$ (corresponding roughly to the top of the control volume; panel b). Each panel includes the upward and downward zero crossings of the water surface level (dotted lines) as a phase reference. The waves propagate through the spatiotemporal domain from the lower left to the upper right corner.

Comparison of Fig. 15e and Fig. $15 \mathrm{f}$ reveals that $\Delta q_{n b}$ and $\Phi_{z}\left(z_{a}\right)$ are of similar magnitude. Hence, both the horizontal sediment influx along 

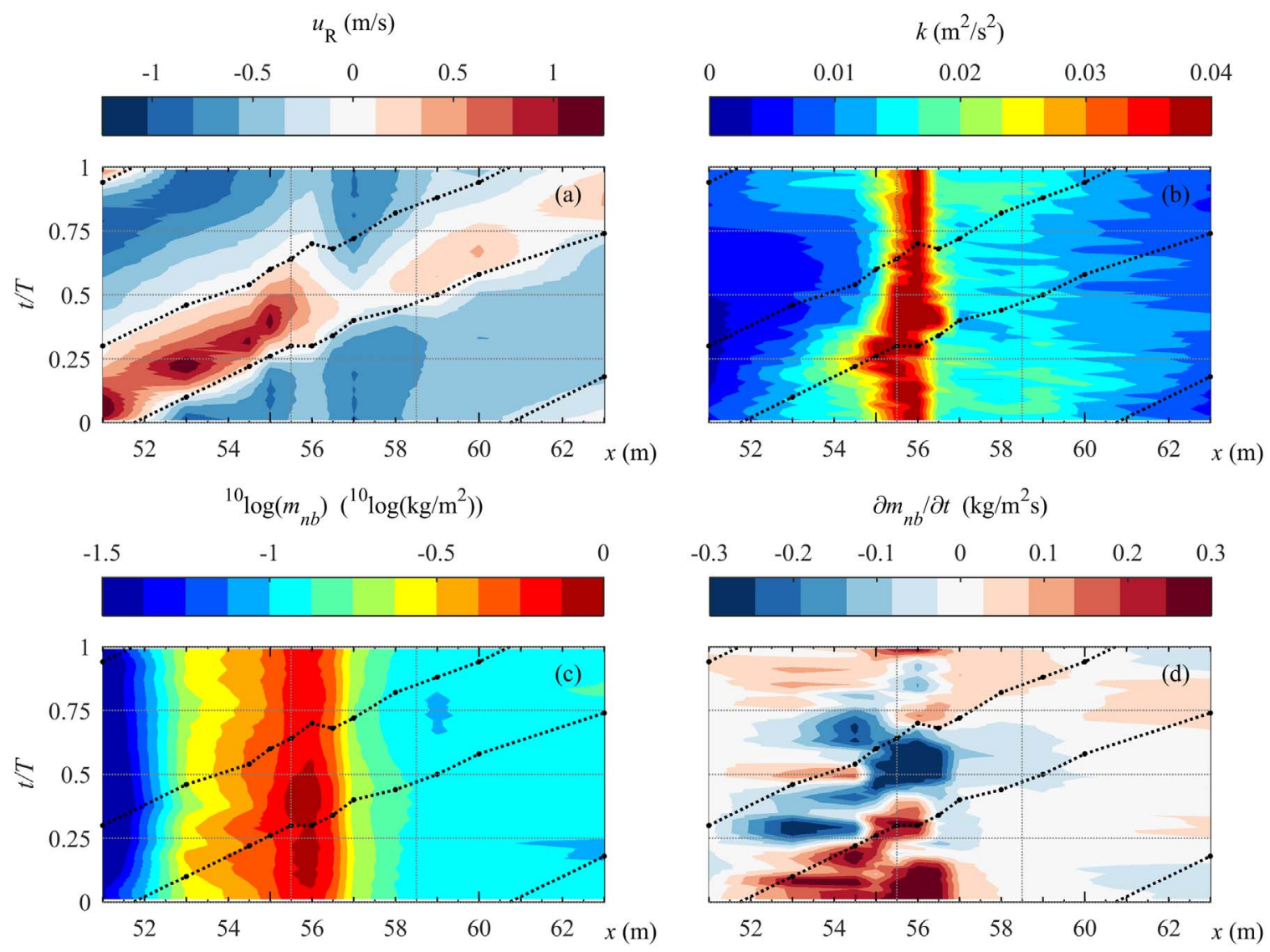

$$
\Delta q_{n b}=-\partial q_{n b} / \partial x\left(\mathrm{~kg} / \mathrm{m}^{2} \mathrm{~s}\right)
$$
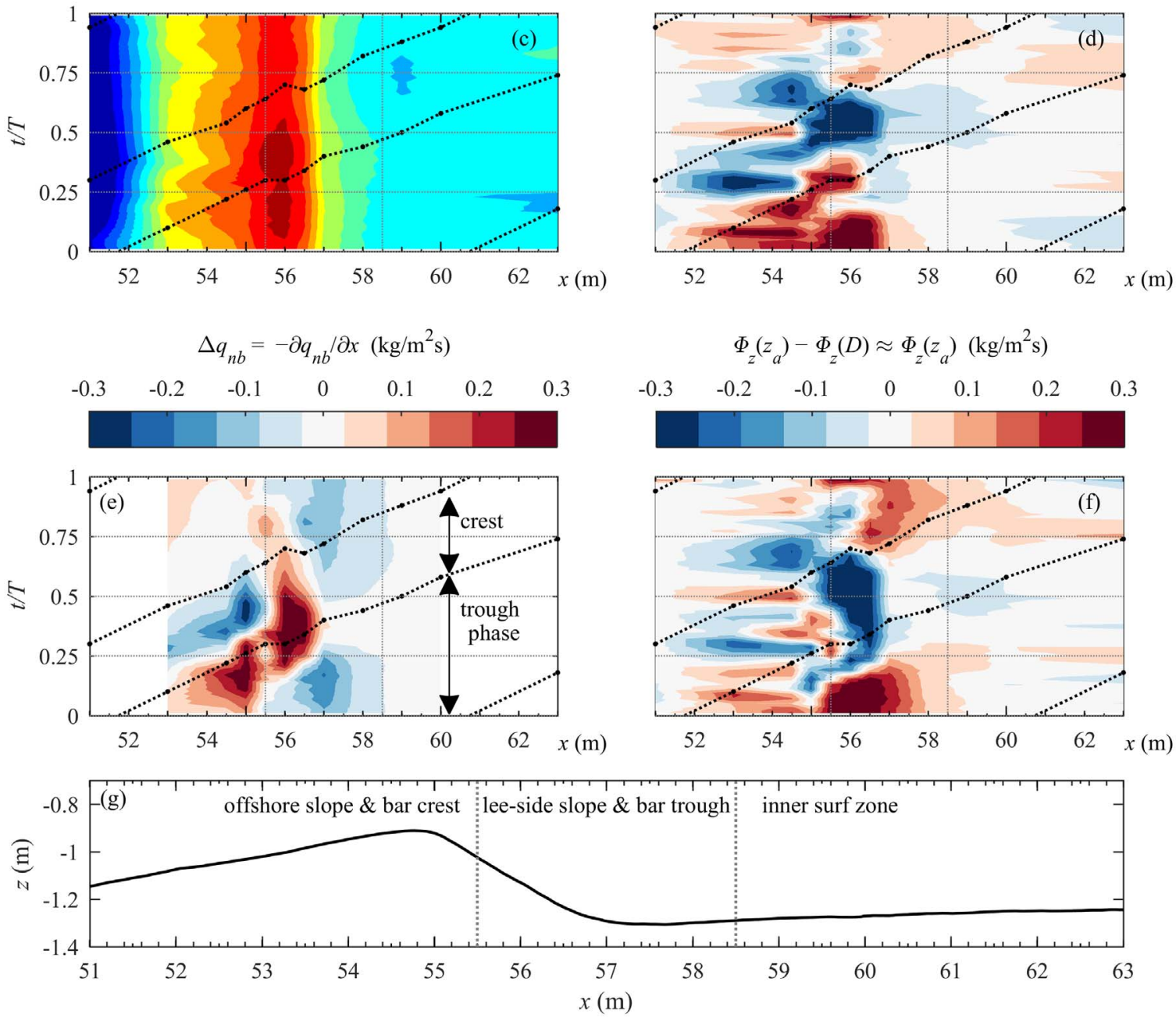

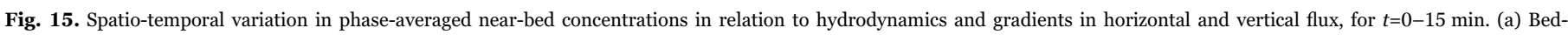

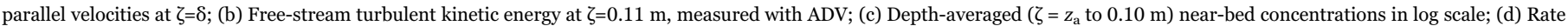

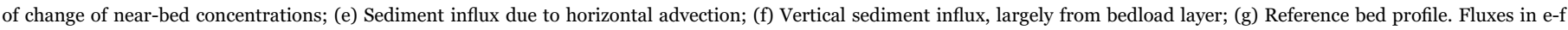

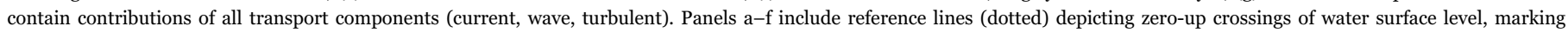
reversal between wave crest and trough phase (dotted). In the analysis distinction is made between three regions, divided by vertical grey lines in all panels (see text).

the bed and the vertical influx between the bedload and suspension layer induce temporal changes in the suspended mass (Fig. 15d).

Between $x=51.0$ and $55.0 \mathrm{~m}$, i.e. at the shoaling and breaking region up to the bar crest, $m_{n b}$ increases (positive $\partial m_{n b} / \partial t$ in Fig. $15 \mathrm{~d}$ ) between the middle of the wave trough phase until shortly after flow reversal and decreases during the wave crest phase (negative $\partial m_{n b} / \partial t$ ). 
Fig. $15 \mathrm{f}$ shows that these temporal changes are partly explained by vertical influx from the bedload into the suspension layer, with $\Phi_{z}\left(z_{a}\right)$ $>0$ around the zero-up crossing when periodic velocities are directed upward and sediment is entrained, and $\Phi_{z}\left(z_{a}\right)<0$ during the crest phase when suspended particles settle down. The phase behavior of $\partial m_{n b} / \partial t$ is further explained by the horizontal sediment influx $\Delta q_{n b}$ (Fig. 15e). During the wave trough phase, suspended sediment is advected offshore from the high-concentration breaking region to the low-concentration shoaling zone, leading to a positive influx of sediment $\left(\Delta q_{n b}>0\right)$ and an increase in suspended mass at $x=51.0-$ $55.0 \mathrm{~m}$. During the wave crest phase, a reverse pattern occurs as suspended particles are advected onshore from the shoaling to the breaking zone, leading to $\Delta q_{n b}<0$ and a decrease in $m_{n b}$. This excursion of suspended sediment between breaking and shoaling locations explains the concentration changes above the WBL $(\zeta>\delta)$ that were previously identified in Fig. 7 (at $x=53.0-55.0 \mathrm{~m}$ ).

In the breaking region between bar crest and bar trough $(x=55.5-$ $58.0 \mathrm{~m}$ ), the temporal behavior of horizontal and vertical advection differs notably from the locations offshore from the bar crest. Fig. $15 f$ shows that at the bar trough $(x=57.0-58.0 \mathrm{~m})$, a positive vertical influx from the bedload to the suspension layer occurs during most of the wave trough phase $(t / T \approx 0.75-0.25$ in next wave cycle). This net pick-up at the bar trough is due to the combination of the large offshore-directed velocities (Fig. 15a) and the presence of breakinggenerated TKE that arrives at the bed during the wave trough phase (Fig. 15b). Phase-averaged velocities are almost continuously directed offshore at these locations, leading to rapid offshore advection of the entrained sediment along the steep shoreward slope of the bar towards the bar crest. This explains the predominantly negative horizontal influx (i.e. removal of sediment) at the bar trough $(x=56.5-57.5 \mathrm{~m}$; Fig. 15e). This offshore-advected sediment arrives at the bar crest $(x=$ $55.5-56.0 \mathrm{~m}$ ), leading to a positive horizontal influx during most of the wave cycle (Fig. 15e). This positive horizontal influx is accompanied by a negative vertical influx near the bar crest (Fig. 15f) which indicates net deposition of suspended sediment. This deposition occurs particularly during the wave crest phase, when sediment concentrations are highest.

At the inner surf zone the temporal changes in suspended mass $\partial m_{n b} / \partial t$ are much smaller than at the shoaling and breaking locations; no distinct patterns in horizontal and vertical sediment influx are identified.

\section{Discussion}

Near-bed concentration changes are not only due to local pick-up and deposition processes, but are also due to horizontal influx of sediment that results from cross-shore non-uniformity in the horizontal sediment fluxes. The latter also occurs in WBLs under non-breaking waves because the velocity field changes in space and time as a wave progresses. Kranenburg et al. [26] showed that horizontal sediment fluxes converge during the wave crest phase and diverge during the wave trough phase, leading to highest concentrations under the wave crest and lowest concentrations under the wave trough. Compared to these non-breaking wave observations, the phase behavior at shoaling locations in the present study is slightly shifted: maximum concentrations are reached around trough-to-crest flow reversal, i.e. before the passing of the wave crest and at an earlier stage than under nonbreaking waves. This is explained by the strong cross-shore variation in suspended sediment concentrations inside and outside the WBL near the breaking point, leading to a much higher influx of sediment during the wave trough phase (arrival of high-concentration) and an earlier local maximum in suspended sediment concentrations.

The observed offshore-onshore excursion of suspended sediment between the breaking and shoaling zone is consistent with field observations under plunging breakers by Beach and Sternberg [6], who observed a 'cloud of sediment sweeping back and forth'. Note that the suspended sediment that enters the shoaling zone during the trough phase roughly balances the sediment leaving the shoaling zone during the crest phase (Fig. 15e). Hence, sediment particles seem to remain in suspension - or the settling of suspended particles balances the entrainment of particles from the bedload layer - during the complete wave cycle while following the orbital flow. This sediment excursion is consistent with the excursion of TKE highlighted in van der Zanden et al. [62], suggesting that suspended sediment particles are trapped in turbulent vortices that are partly breaking-generated.

It has been suggested that the phase-coupling of TKE and suspended sediment concentrations under plunging breakers may enhance the wave-related suspended sediment transport [10,13,58,7]. However, in the present study, the particles trapped in turbulent vortices are advected back and forth, resulting in local (Eulerian) concentration changes but generally not in a net wave-related transport contribution at elevations outside the WBL. This relates directly to the relatively low intra-wave variation in TKE for the present conditions: TKE does not decay fully within a wave period and significant residual turbulence persists into the next wave cycle [62]. It is anticipated that longer-period or random waves, which yield stronger temporal variation in TKE than the waves in the present study, would result in stronger intra-wave variation of outer-flow concentrations and in higher wave-related outer-flow suspended sediment fluxes. The latter may also explain why field measurements at fine-to-medium sand beaches have shown significant wave-related fluxes at outer-flow elevations in the breaking region $[34,37,46]$.

Outer-flow concentration profiles above the breaker bar crest are approximately depth-uniform and high sediment concentrations occur in the outer flow up to wave crest level. These high concentrations are not only explained by vertical mixing by orbital velocities and (breaking-generated) turbulence, but also by vertical advective sediment fluxes due to non-zero time-averaged vertical resulting from (i) a vertical component of the undertow as it follows the bar geometry, and (ii) cross-shore gradients in the bed-parallel undertow velocities that are balanced by a velocity in bed-normal direction (i.e. because of fluid mass conservation). For the present study, time-averaged velocities follow a circulation cell with downward velocities above the bar trough and upward velocities above the bar crest. In morphodynamic models all three mixing mechanisms (turbulent, wave-related, time-averaged advection) should be taken into account. Furthermore, morphodynamic models should account for the significant contribution of suspended sediment flux occurring between wave trough and wave crest level.

In terms of sand transport modeling, empirical formulations for enhanced wave-related suspended transport reaching elevations far outside the WBL have been proposed for the breaking region [64]. This approach is partly supported by the present measurements. Indeed, the magnitude of the wave-related transport is enhanced in the breaking region, especially at the bar crest, compared to the shoaling zone (Fig. 8; Fig. 12a). However, the wave-related fluxes generally do not extend vertically into the outer flow, but remain confined to the WBL as is also the case for non-breaking waves (c.f. [47]). An exception is one location along the shoreward bar slope, where near-bed TKE is highest and where significant wave-related transport occurs above the WBL.

Time-averaged near-bed concentrations are largely controlled by local pick-up. Most commonly-used formulae for reference concentration $C_{O}$ are based on estimates of bed shear stress by periodic and timeaveraged near-bed velocities (e.g. [32,64]) and will likely predict highest pick-up and offshore-directed suspended transport rates at the bar crest (c.f. [23]). In the present study, maximum pick-up rates are found shoreward from the bar crest along the shoreward-facing bar slope, where highest near-bed TKE occurs. Consistent with other surf zone observations (e.g. [2,66]), the present study shows that $C_{0}$ correlates poorly with $\bar{u}$ and $\tilde{u}_{r m s}$. Hence, the cross-shore variation in sediment pick-up cannot be explained by bed shear stress purely by periodic and time-averaged velocities. Instead, $C_{0}$ correlates signifi- 
cantly with near-bed TKE, suggesting that breaking-generated turbulence is an important driver for sediment pick-up.

This implies that $C_{0}$ models in the breaking zone can be considerably improved through parameterizations of near-bed turbulence effects on sediment entrainment. Although such models have already been proposed (e.g. [52,20,36]), it should be noted that it is not trivial to quantify near-bed TKE using existing turbulence closure models [11]. Alternatives are $C_{0}$ or pick-up models that are based on breakingwave characteristics such as the relative wave height [27], the wave energy dissipation due to breaking [24,50], or the surface roller induced shear stress on the water surface [51]. However, the present study shows that near-bed TKE is not fully determined by local 1D processes, i.e. production at the bed and water surface followed by vertical advection/diffusion; instead, TKE spreads in the cross-shore direction through advection by the undertow and orbital flow [62]. Consequently, the region at which sediment pick-up is enhanced extends to shoaling locations adjacent to the breaking zone (see Fig. 14bc).

Some morphodynamic models (e.g. XBeach: $[45,15])$ resolve the depth-integrated instead of the depth-dependent advection and diffusion of suspended sediment. Wave breaking turbulence effects on the suspended sediment load can be accounted for in various ways, e.g. by adding the rms turbulent velocity to the near-bed stirring velocity [15], by considering a breaking-induced suspended sediment load in addition to the bed-shear-based load [44], or by assuming that near-bed TKE is the sole driver for the depth-averaged suspended load (e.g. [38]). A possible advantage of these approaches is that the complex effects of wave breaking turbulence on the suspended sediment load, i.e. the enhancing effects on sediment pick-up and on vertical mixing, are all accounted for through one parameter: the near-bed turbulent kinetic energy $k_{\mathrm{b}}$. The present study suggests that $k_{b}$ is indeed a good predictor for the depth-integrated suspended load in the breaking region - possibly even better than the periodic bed shear, hence the approach by Reniers et al. [38] seems to be preferred over the present XBeach [15] approach.

Although physically meaningful, the validation of all these approaches against high-resolution suspended sediment load measurements under breaking waves seems rather limited and would make a good topic for further research. The further development of suspended sand transport formulations for surf zone conditions would likely benefit from high-resolution data of near-bed concentrations, turbulence, and wave characteristics for a wider range of breaking waves and sediment characteristics than covered by the present and previous studies. Controlled flow tunnel or flume studies with artificial grid turbulence (c.f. [54,36]), where the external turbulence is systematically raised, may help to incorporate turbulence effects in existing $C_{0}$ formulations. All data in the present paper are available upon request with the first author.

\section{Conclusions}

The effects of wave breaking on suspended sediment processes were examined through a large-scale wave flume experiment, involving regular plunging breaking waves over a barred beach of medium sand. Measurements of suspended sediment concentrations and fluxes were obtained at 12 locations from the shoaling to the inner surf zone and extend a large part of the water column, with particularly high resolution in the lowest $0.10 \mathrm{~m}$ that includes the wave bottom boundary layer (WBL). The measurements were related to observations of near-bed hydrodynamics including turbulent kinetic energy (TKE), as presented in van der Zanden et al. [62], and yield new insights into sediment pick-up, deposition and horizontal advection in the breaking region. Based on the results we conclude the following:

1. Breaking-generated TKE that invades the WBL has a significant effect on near-bed sediment concentrations. Sediment pick-up rates increase by an order of magnitude between the shoaling and breaking regions. Wave-averaged reference concentrations in the breaking region correlate better with near-bed TKE than with bedparallel periodic velocities, suggesting that breaking-generated turbulence is an important driver for sediment pick-up. At an intrawave time scale, suspended sediment concentrations are phasecoherent with near-bed TKE.

2. Sediment concentration profiles are Rouse-shaped with a strong increase in concentration inside the WBL. Suspended sediment is particularly strongly mixed above the bar crest, where outer-flow concentrations are nearly depth-uniform. This vertical mixing is attributed to the combination of energetic breaking-generated vortices, the strongly asymmetric wave shape (strong upward wave-related advection), and upward-directed wave-averaged velocities resulting from a time-averaged fluid circulation cell.

3. Net (i.e. wave-averaged) suspended sediment fluxes reveal a complex pattern with alternating onshore and offshore-directed constituents. In the shoaling region and breaking locations up to the bar crest, net sediment fluxes are directed onshore inside the WBL but offshore in the outer flow. Above the breaker bar crest a substantial onshore-directed suspended transport contribution occurs above wave trough level. In the breaking region along the shoreward slope of the bar and inside the inner surf zone, net suspended sediment fluxes are offshore-directed over most of the water column.

4. Net outer-flow suspended fluxes are generally current-related and offshore-directed due to the undertow. Significant net wave-related fluxes are observed at shoaling and breaking locations, where they are directed onshore and are generally confined to the WBL. Only at one location, i.e. the breaker location with highest near-bed TKE and near-bed concentrations, does the net wave-related flux extend vertically to outer-flow elevations. At this location, the combination of high turbulence levels and a strong cross-shore concentration gradient leads to a net onshore diffusive flux $\overline{u^{\prime} C^{\prime}}$.

5. Sediment flux gradients were quantified to study the advection and the pick-up and deposition of suspended sediment. At a waveaveraged time scale, sediment grains are entrained from the bed in the bar trough region, are advected offshore by the undertow, and are deposited in the region covering the shoaling zone, bar crest, and the upper part of the steep onshore bar slope. Near-bed concentrations are largely ( > 90\%) determined by local pick-up; contributions of cross-shore advected sediment are minor.

6. Offshore from the bar crest, concentration changes are primarily due to cross-shore advection by orbital velocities. Suspended particles travel back and forth between the breaking and shoaling zone, yielding an increase in sediment concentrations at shoaling locations during the wave trough phase and a decrease in concentrations during the wave crest phase. This onshore-offshore excursion is consistent with the spatio-temporal variation in TKE, which suggests that sediment particles are trapped in breaking-generated vortices that are advected back and forth following the orbital motion.

7. Shoreward from the bar crest, concentration changes are due to cross-shore-varying and time-varying pick-up and deposition rates and due to cross-shore gradients in periodic and time-averaged velocities. Sediment is entrained in the bar trough especially during the wave trough phase, when both near-bed velocity magnitude and breaking-generated TKE arriving at the bed are highest. The entrained particles are almost instantly advected offshore and are deposited near the bar crest during the wave crest phase when velocity magnitudes reduce.

\section{Acknowledgments}

The authors wish to thank the staff of CIEMLAB (Joaquim Sospedra, Oscar Galego and Ricardo Torres) and Mick Poppe from the University of Twente for their contributions to the experiments. We are also grateful to fellow SINBAD researchers and to prof. Peter Thorne for their feedback 
on preliminary results and to two anonymous reviewers and prof. dr. Suzanne J.M.H. Hulscher for their feedback on the draft manuscript. The research presented in this paper is part of the SINBAD project, funded by STW (12058) and EPSRC (EP/J00507X/1, EP/J005541/1). We further acknowledge the European Community's FP7 project Hydralab IV (contract no. 261520) for funding the accompanying SandT-Pro experiments and the ACVP development by CNRS-LEGI (D. Hurther, P.-A. Barraud, J.-M. Barnoud).

\section{References}

[1] T. Aagaard, M.G. Hughes, Breaker turbulence and sediment suspension in the surf zone, Mar. Geol. 271 (3-4) (2010) 250-259. http://dx.doi.org/10.1016/j.margeo.2010.02.019.

[2] T. Aagaard, S.G. Jensen, Sediment concentration and vertical mixing under breaking waves, Mar. Geol. 336 (2013) 146-159. http://dx.doi.org/10.1016/ j.margeo.2012.11.015.

[3] N.W.H. Allsop, S.S.L. Hettiarachchi, Reflections from Coastal Structures. Proc. 21st International Conference on Coastal Engineering, American Society of Civil Engineers, 1988, pp. 782-794.

[4] R.A. Bagnold, The flow of cohesionless grains in fluids, Philos. Trans. R. Soc. A: Math. Phys. Eng. Sci. 249 (964) (1956) 235-297. http://dx.doi.org/10.1098/ rsta.1956.0020.

[5] T.E. Baldock, M.R. Tomkins, P. Nielsen, M.G. Hughes, Settling velocity of sediments at high concentrations, Coast. Eng. 51 (1) (2004) 91-100. http:// dx.doi.org/10.1016/j. coastaleng .2003.12.004.

[6] R.A. Beach, R.W. Sternberg, Suspended-sediment transport in the surf zone: response to breaking waves, Cont. Shelf Res. 16 (15) (1996) 1989-2003.

[7] M. Boers, Surf Zone Turbulence, PhD Thesis, TU Delft, The Netherlands, 2005.

[8] S.J. Blott, K. Pye, GRADISTAT: a grain size distribution and statistics package for the analysis of unconsolidated sediments, Earth Surf. Proc. Landf. 26 (11) (2001) 1237-1248. http://dx.doi.org/10.1002/esp.261.

[9] J.J. Bosman, E.T.J.M. van der Velden, C.H. Hulsbergen, Sediment concentration measurement by transverse suction, Coast. Eng. 11 (4) (1987) 353-370. http:// dx.doi.org/10.1016/0378-3839(87)90033-0.

[10] J.A. Brinkkemper, A.T.M. de Bakker, B.G. Ruessink, Intra-wave sand suspension in the shoaling and surf zone of a field-scale laboratory beach, J. Geophys. Res.: Earth Surf. 122 (1) (2017) 356-370. http://dx.doi.org/10.1002/2016jf004061.

[11] S.A. Brown, D.M. Greaves, V. Magar, D.C. Conley, Evaluation of turbulence closure models under spilling and plunging breakers in the surf zone, Coast. Eng. 114 (2016) 177-193. http://dx.doi.org/10.1016/j.coastaleng.2016.04.002.

[12] D.T. Cox, N. Kobayashi, Identification of intense, intermittent coherent motions under shoaling and breaking waves, J. Geophys. Res.-Ocean. 105 (C6) (2000) 14223-14236. http://dx.doi.org/10.1029/2000JC900048.

[13] F. De Serio, M. Mossa, Experimental study on the hydrodynamics of regular breaking waves, Coast. Eng. 53 (1) (2006) 99-113. http://dx.doi.org/10.1016/ j.coastaleng.2005.09.021.

[14] R. Deigaard, J.B. Jakobsen, J. Fredsøe, Net sediment transport under wave groups and bound long waves, J. Geophys. Res. 104 (C6) (1999) 13559. http://dx.doi.org/ $10.1029 / 1999 j \mathrm{jc} 900072$.

[15] Deltares, XBeach user manual. Online user manual at $\langle\mathrm{http}: / /$ xbeach.readthedocs. io/ $\rangle$, visited at 15/01/2017, 2017.

[16] J.P. Downing, R.A. Beach, Laboratory apparatus for calibrating optical suspended solids sensors, Mar. Geol. 86 (2-3) (1989) 243-249. http://dx.doi.org/10.1016/ 0025-3227(89)90053-4.

[17] S. Elgar, E.L. Gallagher, R.T. Guza, Nearshore sandbar migration, J. Geophys. Res. 106 (C6) (2001) 11623. http://dx. doi.org/10.1029/2000jc000389.

[18] D.L. Foster, A.J. Bowen, R.A. Holman, P. Natoo, Field evidence of pressure gradient induced incipient motion, J. Geophys. Res. 111 (C5) (2006). http:// dx.doi.org/10.1029/2004jc002863.

[19] F. Hoefel, S. Elgar, Wave-induced sediment transport and sandbar migration, Science 299 (5614) (2003) 1885-1887. http://dx.doi.org/10.1126/ science.1081448.

[20] T.-J. Hsu, P.L.-F. Liu, Toward modeling turbulent suspension of sand in the nearshore, J. Geophys. Res. 109 (C6) (2004). http://dx.doi.org/10.1029/ $2003 \mathrm{jc} 002240$.

[21] D. Hurther, P.D. Thorne, Suspension and near-bed load sediment transport processes above a migrating, sand-rippled bed under shoaling waves, J. Geophys. Res. 116 (C7) (2011). http://dx.doi.org/10.1029/2010jc006774.

[22] D. Hurther, P.D. Thorne, M. Bricault, U. Lemmin, J.M. Barnoud, A multi-frequency Acoustic Concentration and Velocity Profiler (ACVP) for boundary layer measurements of fine-scale flow and sediment transport processes, Coast. Eng. 58 (7) (2011) 594-605. http://dx.doi.org/10.1016/j.coastaleng.2011.01.006.

[23] N.G. Jacobsen, J. Fredsoe, Formation and development of a breaker bar under regular waves. Part 2: sediment transport and morphology, Coast. Eng. 88 (2014) 55-68. http://dx.doi.org/10.1016/j.coastaleng.2014.01.015.

[24] N. Kobayashi, B.D. Johnson, Sand suspension, storage, advection, and settling in surf and swash zones, J. Geophys. Res. 106 (C5) (2001) 9363. http://dx.doi.org/ $10.1029 / 2000 j \mathrm{jc000557.}$

[25] N. Kobayashi, H. Zhao, Y. Tega, Suspended sand transport in surf zones, J. Geophys. Res. 110 (C12) (2005). http://dx.doi.org/10.1029/2004jc002853.

[26] W.M. Kranenburg, J.S. Ribberink, J.J.L.M. Schretlen, R.E. Uittenbogaard, Sand transport beneath waves: the role of progressive wave streaming and other free surface effects, J. Geophys. Res.: Earth Surf. 118 (1) (2013) 122-139. http:// dx.doi.org/10.1029/2012jf002427.

[27] G.P. Mocke, G.G. Smith, Wave breaker turbulence as a mechanism for sediment suspension, in: Proceedings 23rd International Conference on Coastal Engineering. Venice, Italy, 1992, pp. 2279-2292.

[28] K. Nadaoka, S. Ueno, T. Igarashi, Sediment suspension due to large scale eddies in the surf zone, in: Proceedings of the 21st International Conference on Coastal Engineering, Torremolimos, Spain, 1988, pp. 1646-1660. doi.

[29] S. Naqshband, J.S. Ribberink, D. Hurther, S.J.M.H. Hulscher, Bed load and suspended load contributions to migrating sand dunes in equilibrium, J. Geophys. Res.-Earth Surf. 119 (5) (2014) 1043-1063. http://dx.doi.org/10.1002/ 2013jf003043.

[30] S. Naqshband, J. Ribberink, D. Hurther, P. - A. Barraud, S.J.M.H. Hulscher, Experimental evidence for turbulent sediment flux constituting a large portion of total sediment flux along migrating sand dunes, Geophys. Res. Lett. (2014). http:// dx.doi.org/10.1002/2014GL062322.

[31] P. Nielsen, Field-measurements of time-averaged suspended sediment concentrations under waves, Coast. Eng. 8 (1) (1984) 51-72. http://dx.doi.org/10.1016/ 0378-3839(84)90022-X.

[32] P. Nielsen, Suspended sediment concentrations under waves, Coast. Eng. 10 (1) (1986) 23-31. http://dx.doi.org/10.1016/0378-3839(86)90037-2.

[33] P. Nielsen, Coastal Bottom Boundary Layers and Sediment Transport., World Scientific, Singapore, 1992.

[34] A.S. Ogston, R.W. Sternberg, On the importance of nearbed sediment flux measurements for estimating sediment transport in the surf zone, Cont. Shelf Res. 15 (13) (1995) 1515-1524. http://dx.doi.org/10.1016/0278-4343(95)00036-z.

[35] A.S. Ogston, R.W. Sternberg, Effect of wave breaking on sediment eddy diffusivity, suspended-sediment and longshore sediment flux profiles in the surf zone, Cont. Shelf Res. 22 (4) (2002) 633-655. http://dx.doi.org/10.1016/s0278-4343(01) 00033-4.

[36] A. Okayasu, K. Fujii, M. Isobe, Effect of external turbulence on sediment pickup rate, in: Proceedings 32nd International Conference on Coastal Engineering, 2010, p. 13.

[37] P.D. Osborne, B. Greenwood, Frequency-dependent cross-shore suspended sediment transport .1. A non-barred shoreface, Mar. Geol. 106 (1-2) (1992) 1-24.

[38] A.J.H.M. Reniers, E.L. Gallagher, J.H. MacMahan, J.A. Brown, A.A. van Rooijen, J.S.M.V. de Vries, B.C. van Prooijen, Observations and modeling of steep-beach grain-size variability, J. Geophys. Res.-Ocean. 118 (2) (2013) 577-591. http:// dx.doi.org/10.1029/2012jc008073.

[39] T. Revil-Baudard, J. Chauchat, D. Hurther, P.-A. Barraud, Investigation of sheetflow processes based on novel acoustic high-resolution velocity and concentration measurements, J. Fluid Mech. 767 (2015) 1-30. http://dx.doi.org/10.1017/ jfm.2015.23.

[40] J.S. Ribberink, Bed-load transport for steady flows and unsteady oscillatory flows, Coast. Eng. 34 (1998) 59-82.

[41] J.S. Ribberink, A.A. Al-Salem, Sheet flow and suspension of sand in oscillatory boundary-layers, Coast. Eng. 25 (3-4) (1995) 205-225. http://dx.doi.org/10.1016/ 0378-3839(95)00003-T.

[42] J.S. Ribberink, D.A. Van, der, A, J. Van der Zanden, T. O'Donoghue, D. Hurther, I. Cáceres, P.D. Thorne, SandT-Pro: sediment transport measurements under irregular and breaking waves, in: P. Lynett (Ed.)Proceedings of the 34th International Conference on Coastal Engineering, Seoul, Korea, Coastal Engineering Research Council, Seoul, Korea, 2014, p. 14. http://dx.doi.org/ 10.9753/icce.v34.sediment.1.

[43] J.A. Roelvink, A. Reniers, LIP 11D Delta Flume Experiments - Data report. W. D. Hydraulics, Delft, The Netherlands, 1995.

[44] J.A. Roelvink, M.J.F. Stive, Bar-generating cross-shore flow mechanisms on a beach, J. Geophys. Res.-Oceans 94 (c4) (1989) 4785-4800. http://dx.doi.org/ 10.1029/Jc094ic04p04785.

[45] D. Roelvink, A. Reniers, A. van Dongeren, J.V. de Vries, R. McCall, J. Lescinski, Modelling storm impacts on beaches, dunes and barrier islands, Coast. Eng. 56 (11-12) (2009) 1133-1152.

[46] B.G. Ruessink, K.T. Houwman, P. Hoekstra, The systematic contribution of transporting mechanisms to the cross-shore sediment transport in water depths of 3-9 m, Mar. Geol. 152 (4) (1998) 295-324. http://dx.doi.org/10.1016/S00253227(98)00133-9.

[47] J.L.M. Schretlen, Sand Transport Under Full-scale Progressive Surface Waves, PhD Thesis, University of Twente, The Netherlands, 2012.

[48] N.V. Scott, T.J. Hsu, D. Cox, Steep wave, turbulence, and sediment concentration statistics beneath a breaking wave field and their implications for sediment transport, Cont. Shelf Res. 29 (20) (2009) 2303-2317. http://dx.doi.org/10.1016/ j.csr.2009.09.008.

[49] E.R. Smith, N.C. Kraus, Laboratory study of wave-breaking over bars and artificial reefs, J. Waterw. Port. Coast. Ocean. Eng. 117 (4) (1991) 307-325. http:// dx.doi.org/10.1061/(asce)0733-950x(1991)117:4(307).

[50] G.G. Smith, G.P. Mocke, Sediment Suspension by Turbulence in the Surf Zone, World Scientific, Le Havre, France, 1993, pp. 357-387 (Proc. Euromech 1993).

[51] K. Spielmann, D. Astruc, O. Thual, Analysis of some key parametrizations in a beach profile morphodynamical model, Coast. Eng. 51 (10) (2004) 1021-1049.

[52] H. Steetzel, Cross-shore Transport During Storm Surges, PhD thesis, Delft University of Technology, 1993.

[53] B.M. Sumer, H.A.A. Guner, N.M. Hansen, D.R. Fuhrman, J. Fredsøe, Laboratory observations of flow and sediment transport induced by plunging regular waves, $\mathrm{J}$. Geophys. Res.: Ocean. 118 (11) (2013) 6161-6182. http://dx.doi.org/10.1002/ 2013jc009324. 
[54] B.M. Sumer, L.H.C. Chua, N.S. Cheng, J. Fredsoe, Influence of turbulence on bed load sediment transport, J. Hydraul. Eng.-ASCE 129 (8) (2003) 585-596. http:// dx.doi.org/10.1061/(Asce)0733-9429(2003)129:8(585).

[55] I.A. Svendsen, P.A. Madsen, J. Buhr Hansen, Wave Characteristics in the Surf Zone, American Society of Civil Engineers, Hamburg, Germany, 1978, pp. 520-539 (Proc. 16th Conf. Coastal Eng).

[56] P.D. Thorne, D. Hurther, An overview on the use of backscattered sound for measuring suspended particle size and concentration profiles in non-cohesive inorganic sediment transport studies, Cont. Shelf Res. 73 (2014) 97-118. http:// dx.doi.org/10.1016/j.csr.2013.10.017.

[57] E.B. Thornton, R.T. Humiston, W. Birkemeier, Bar/trough generation on a natural beach, J. Geophys. Res.-Ocean. 101 (C5) (1996) 12097-12110. http://dx.doi.org/ 10.1029/96jc00209.

[58] F.C.K. Ting J.T. Kirby, Observation of Undertow and Turbulence in a Laboratory Surf Zone, Coast. Eng. 24 (1-2) (1994) 51-80. http://dx.doi.org/10.1016/03783839(94)90026-4.

[59] J.J. Van der Werf, J.S. Doucette, T. O'Donoghue, J.S. Ribberink, Detailed measurements of velocities and suspended sand concentrations over full-scale ripples in regular oscillatory flow, J. Geophys. Res. 112 (F2) (2007). http:// dx.doi.org/10.1029/2006jf000614.

[60] J.J. Van der Werf, J. Magar, K. Malarkey, Guizien, T. O’Donoghue, 2DV modelling of sediment transport processes over full-scale ripples in regular asymmetric oscillatory flow, Cont. Shelf Res. 28 (8) (2008) 1040-1056. http://dx.doi.org/ 10.1016/j.csr.2008.02.007.

[61] J. Van der Zanden, Sand Transport Processes in the Surf and Swash Zones, Ph.D. thesis, University of Twente, Netherlands, 2016, p. 202. http://dx.doi.org/ 10.3990/1.9789036542456.

[62] J. Van der Zanden, D.A. van der A, D. Hurther, I. Cáceres, T. O'Donoghue, J.S. Ribberink, Near-bed hydrodynamics and turbulence below a large-scale plunging breaking wave over a mobile barred bed profile, J. Geophys. Res.: Ocean.
121 (8) (2016) 6482-6506. http://dx.doi.org/10.1002/2016jc011909.

[63] L.C. Van Rijn, Unified view of sediment transport by currents and waves. I initiation of motion, bed roughness, and bed-load transport, J. Hydraul. Eng.-ASCE 133 (6) (2007) 649-667. http://dx.doi.org/10.1061/(Asce)0733-9429(2007) 133:6(649).

[64] L.C. Van Rijn, Unified view of sediment transport by currents and waves. II: suspended transport, J. Hydraul. Eng. 133 (6) (2007) 668-689. http://dx.doi.org/ 10.1061/(asce)0733-9429(2007)133:6(668).

[65] L.C. Van Rijn, J.S. Ribberink, J.J. van der Werf, D.J.R. Walstra, Coastal sediment dynamics: recent advances and future research needs, J. Hydraul. Res. 51 (5) (2013) 475-493. http://dx.doi.org/10.1080/00221686.2013.849297.

[66] G. Voulgaris, M.B. Collins, Sediment resuspension on beaches: response to breaking waves, Mar. Geol. 167 (1-2) (2000) 167-187. http://dx.doi.org/10.1016/ S0025-3227(00)00025-6.

[67] Van Thiel de Vries, J.S.M., M.R.A. van Gent, D.J.R. Walstra, A.J.H.M. Reniers, Analysis of dune erosion processes in large-scale flume experiments, Coast. Eng. 55 (12) (2008) 1028-1040. http://dx.doi.org/10.1016/j.coastaleng.2008.04.004.

[68] H.-D. Yoon, D. Cox, N. Mori, Parameterization of time-averaged suspended sediment concentration in the nearshore, Water 7 (11) (2015) 6228-6243. http:// dx.doi.org/10.3390/w7116228.

[69] H.D. Yoon, D.T. Cox, Cross-shore variation of intermittent sediment suspension and turbulence induced by depth-limited wave breaking, Cont. Shelf Res. 47 (2012) 93-106. http://dx.doi.org/10.1016/j.csr.2012.07.001.

[70] Y. Yu, R.W. Sternberg, R.A. Beach, Kinematics of breaking waves and associated suspended sediment in the nearshore zone, Cont. Shelf Res. 13 (11) (1993) 1219-1242. http://dx.doi.org/10.1016/0278-4343(93)90050-8.

[71] Z. Zhou, T.-J. Hsu, D. Cox, X. Liu, Large-eddy simulation of wave-breaking induced turbulent coherent structures and suspended sediment transport on a barred beach, J. Geophys. Res.: Ocean. 122 (1) (2017) 207-235. http://dx.doi.org/ 10.1002/2016jc011884. 